\title{
Extreme precipitation linked to temperature over Japan: current evaluation and projected changes with multi-model ensemble downscaling
}

\author{
Sridhara Nayak ${ }^{1} \cdot$ Koji Dairaku $^{1} \cdot$ Izuru Takayabu $^{2} \cdot$ Asuka Suzuki-Parker $^{3}$. \\ Noriko N. Ishizaki ${ }^{1}$
}

Received: 28 December 2016 / Accepted: 16 August 2017 / Published online: 4 October 2017

(C) The Author(s) 2017. This article is an open access publication

\begin{abstract}
Recent studies have revealed that an increase in surface air temperature elevates the intensity of extreme precipitation associated with the increase of water vapor in the atmosphere, according to the principle of the Clausius-Clapeyron (CC) relationship. In this study, (1) we have verified the dependence of extreme precipitation intensity on temperature (CC relationship) under current climate and (2) investigated the projected changes of the $\mathrm{CC}$ relationship over Japan by using multi-model ensemble downscaling experiments of three Regional Climate Models (RCMs) (NHRCM, NRAMS, WRF) forced by JRA25, as well as three General Circulation Models (GCMs) (CCSM4, MIROC5, MRI-CGCM3). Simulated extreme precipitation linked to temperatures from ensemble experiments coincides with observations that place peak temperatures around $19-22{ }^{\circ} \mathrm{C}$. Climate scenarios (RCP4.5) of the late twenty-first century suggest a $2{ }^{\circ} \mathrm{C}$ increase of $2 \mathrm{~m}$ air temperature, an increase in precipitation intensities above $15 \mathrm{~mm} /$ day, and a decrease in weaker precipitation intensities of $10-15 \mathrm{~mm} /$ day. The projected change rate of the mean precipitation intensities
\end{abstract}

This paper is a contribution to the special issue on East Asian Climate under Global Warming: Understanding and Projection, consisting of papers from the East Asian Climate (EAC) community and the 13th EAC International Workshop in Beijing, China on 24-25 March 2016, and coordinated by Jianping Li, Huang-Hsiung Hsu, Wei-Chyung Wang, Kyung-Ja Ha, Tim Li, and Akio Kitoh.

Koji Dairaku

dairaku@bosai.go.jp

1 Integrated Research on Disaster Risk Reduction Division, National Research Institute for Earth Science and Disaster Resilience, 3-1 Tennodai, Tsukuba, Japan

2 Meteorological Research Institute, Tsukuba, Japan

3 Rissho University, Tokyo, Japan per mean change in air temperature over Japan is found to be $2.4 \% /{ }^{\circ} \mathrm{C}$. Extreme precipitation intensity increases with temperatures up to $22^{\circ} \mathrm{C}$ in future climate scenarios, while the peak is $20^{\circ} \mathrm{C}$ for the current climate. Extreme precipitation intensities at higher percentiles are projected to have larger rates of increase $\left(3-5 \% /{ }^{\circ} \mathrm{C}\right.$ in the current climate and $4-6 \% /{ }^{\circ} \mathrm{C}$ in the future climate scenarios). A decrease of precipitation intensity at higher temperatures relates to water vapor availability. An insufficient water vapor supply for saturation at higher temperatures can lead to a decrease in cloud formation and extreme precipitation.

Keywords Extreme Precipitation · Multi-model ensemble downscaling - Clausius-Clapeyron relationship . Precipitation-temperature relationship

\section{Introduction}

According to recent reports from the Intergovernmental Panel on Climate Change (e.g., IPCC 2007, 2012), surface air temperature is projected to rise due to an increase in the concentration of greenhouse gases in the atmosphere. Therefore, more evaporation is expected to occur at the Earth's surface due to warming and, subsequently, more water vapor is likely to become available in the atmosphere. Thus, an increase in the intensity as well as the frequency of extreme precipitation events is anticipated (O'Groisman et al. 2005; Dairaku and Emori 2006; Pall et al. 2007; Gorman and Schneider 2009; IPCC 2012). This may lead to an increase in the frequency of natural disasters such as floods, soil erosion, and water hazards (IPCC 2012).

Several studies (Lenderink and van Meijgaard 2008, 2010; Berg et al. 2009; Hardwick et al. 2010; Shaw et al. 2011; Mishra et al. 2012; Utsumi et al. 2011; Westra et al. 
2014) have investigated the dependence of extreme precipitation events on surface air temperature over different regions and examined their connection to the Clausius-Clapeyron (CC) relationship. The reason for linking the precipitation dependence on temperature with the $\mathrm{CC}$ relationship is based on the principle of the $\mathrm{CC}$ equation, which states that the moisture-holding capacity in the atmosphere increases by $\sim 7 \%$ per degree rise in temperature (Trenberth et al. 2003). Recently, Nayak and Dairaku (2016) obtained that the extreme precipitation intensities exhibits super-CC scaling (i.e., higher than $7 \% /{ }^{\circ} \mathrm{C}$ ) over Japan for the temperatures below $\sim 10{ }^{\circ} \mathrm{C}$ and sub-CC scaling (i.e., less than $7 \% /{ }^{\circ} \mathrm{C}$ ) for temperatures roughly above $10{ }^{\circ} \mathrm{C}$. Lenderink and van Meijgaard $(2008,2010)$ observed CC scaling behavior (i.e., $\sim 7 \% /{ }^{\circ} \mathrm{C}$ ) of extreme hourly precipitation for temperatures below $8-10{ }^{\circ} \mathrm{C}$ and super-CC scaling behavior for temperatures above $10{ }^{\circ} \mathrm{C}$ at De Bilt (Netherlands), Ukkel (Belgium), Barn (Basel), and Zurich (Switzerland). In another study, Mishra et al. (2012) observed sub-CC scaling of extreme hourly precipitation over the western coastal United States and super-CC scaling over the eastern and northern parts of the United States. Hardwick et al. (2010) studied the relationship between precipitation and temperature over Australia. Their results suggest that extreme daily precipitation over Australia follows CC scaling up to $20-26{ }^{\circ} \mathrm{C}$ and a further increase in temperature decreases precipitation. A similar behavior in daily extreme precipitation has also been observed over the islands of Japan (Utsumi et al. 2011). The extreme precipitation intensity over Europe increases with temperature in wintertime and decreases in summertime (Berg et al. 2009). However, the CC scaling behavior of sub-daily and daily precipitation is observed at a similar rate over the islands of Japan and Australia (Hardwick et al. 2010; Utsumi et al. 2011), while this behavior differs at De Bilt, Netherlands (Lenderink and van Meijgaard 2008). These studies clearly indicate that the CC scaling behavior (i.e., the rate of change of extreme precipitation intensities) of sub-daily and daily precipitation varies from region to region (e.g., Shaw et al. 2011), season to season (e.g., Berg et al. 2009), and are mostly dependent on temperature (e.g., Lenderink and van Meijgaard 2008).

Most of the aforementioned studies have been based on observation datasets (e.g., Hardwick et al. 2010; Utsumi et al. 2011; Shaw et al. 2011; Mishra et al. 2012) to examine the CC scaling behavior, while few studies are conducted with GCM (e.g., Pall et al. 2007) and RCM experiments (e.g., Lenderink and van Meijgaard 2008; Berg et al. 2009; Nayak and Dairaku 2016). In our study, we have analyzed the CC scaling behavior by using multi-GCMs $\mathrm{x}$ multiRCMs experiments as well as observation datasets to address the following questions: (1) How robust the relationship of extreme precipitation events, simulated by multi-model ensemble experiments, with temperature over Japan and does the relationship follow an observed CC relationship? (2) What are the influences of RCM/GCM differences on the relationship? (3) What are the projected future changes in the relationship due to global/regional climate change under RCP4.5 scenario?

The dataset and methods used in this study are discussed in Sect. 2. The results are presented in subsequent sections (Study Question-1, and Question-2 in Sect. 3 and Study Question-2 in Sect. 4). Related discussions occur in Sect. 5 and conclusions drawn from the study are provided in the conclusion, Sect. 6 .

\section{Data and methods}

Twenty-one ensemble experiments (see Table 1) using three RCMs [NHRCM (Saito et al. 2006; Ishizaki and Takayabu 2009; Ishizaki et al. 2012), NRAMS (Pielke et al. 1992; Dairaku et al. 2008a, b; lizuka et al. 2012; Tunematsu et al. 2013), and WRF (Skamarock et al. 2008; Kusaka et al. 2012a, b)] were conducted. Three of the experiments were driven by Japanese 25-year Reanalysis [JRA25 (Onogi et al. 2007)] and 18 experiments (nine for the current climate and nine for the future climate) were conducted by three GCMs (CCSM4, MIROC5, and MRI-GCM3). These GCMs were selected based on research conducted by Mizuta et al. (2014). The experiments were conducted over Japan with a $20 \mathrm{~km}$ horizontal grid spacing for two climate periods (the current and the future) with an RCP4.5 scenario. The multi-model downscaling experiments forced by one GCM (MIROC3.2) with an SRES A1B scenario has been detailed in previous studies (Iizumi et al. 2011; Ishizaki et al. 2012; Iizuka et al. 2012; Tsunematsu et al. 2013). In our study, we
Table 1 List of 21 experiments conducted with three RCMs

\begin{tabular}{llllll}
\hline RCMs & Forced by & & Climate period & $\begin{array}{l}\text { Total number of } \\
\text { experiments }\end{array}$ & Horizontal grid spacing \\
\hline NHRCM & Reanalysis & JRA25 & Current & 3 & $20 \mathrm{~km}$ \\
NRAMS & GCMs & CCSM4 & Current & 9 & \\
WRF & & MIROC5 & Future (RCP4.5) & 9 & \\
& & MRI-CGCM3 & & & \\
\hline
\end{tabular}

Three of the experiments were driven by JRA25 and 18 experiments [nine for current climate (1981-2000) and nine for future climate scenarios (2081-2100)] by three GCMs 
analyzed the multi-GCMs x multi-RCMs ensemble downscaling experiments over Japanese land only (see Fig. 1) for the periods 1981-2000 and 2081-2100, hereafter referred to as the current climate and future climate, respectively. The results of the current climate are validated against APHRODITE daily observations (Yasutomi et al. 2011) over Japan.

First, we aggregated the simulated hourly precipitation and temperatures to a daily sum and daily mean, respectively, to compare with APHRODITE datasets. We then computed the frequency distribution of daily precipitation intensity in the bins of $5 \mathrm{~mm} /$ day and daily mean temperature in the bins of $1{ }^{\circ} \mathrm{C}$ using the multi-model ensemble datasets for the future projection of precipitation and temperature over Japan. We stratified the extreme (99th, 95th, 90th, and 75th percentiles) precipitation wet events (defined as $\geq 0.05 \mathrm{~mm} /$ day) based on daily mean temperature in bins of $1{ }^{\circ} \mathrm{C}$ to investigate the dependence of extreme precipitation on temperature. This study looked at average precipitation intensities and temperatures over Japanese land to investigate the overall regional responses of the relationship between temperature and extreme precipitation to regional/ global climate change. We found that most temperature bins contained more than 150 samples, while few temperature bins (such as low- and high-ends of the frequency distribution) contained less than 100 samples. To avoid a sampling error, the temperature bins with less than 150 samples were excluded from subsequent analysis. The rate of change of extreme precipitation intensities (75th, 90th, 99th, and so on) were computed for each climate period (current and future).
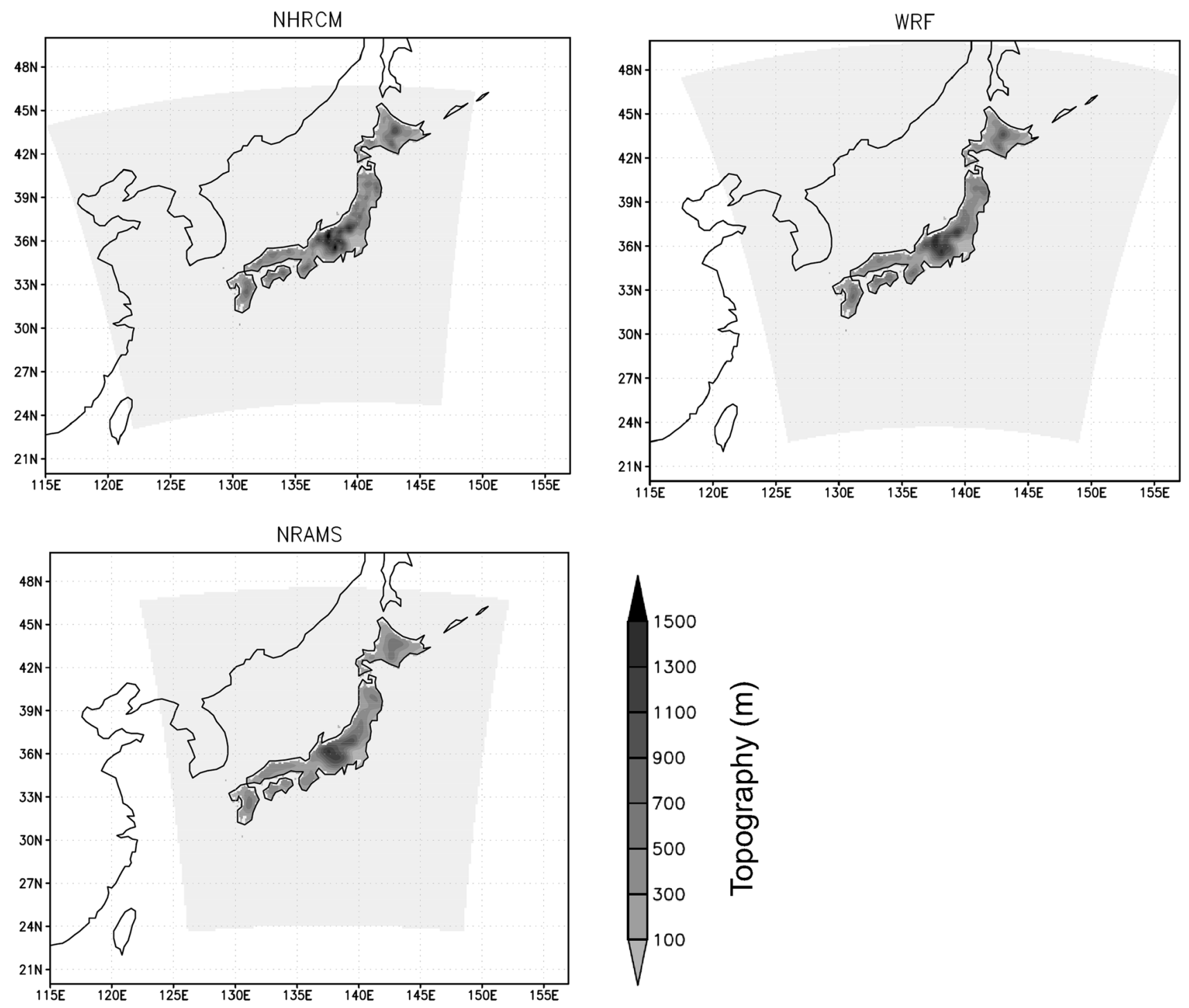

Fig. 1 Study region with topography (unit: m). The shaded area shows the model domain of three RCMs (NHRCM, NRAMS, and WRF) used in this study 
The rate of change of extreme precipitation intensities is computed as follows.

According to the August-Roche-Magnus approximation of the Clausius-Clapeyron relationship, which has been further modified by Alduchov and Eskridge (1996), the saturation vapor pressure $\left(\mathrm{e}_{\mathrm{s}}\right)$ varies exponentially with temperature $\left(\mathrm{T}\right.$, in $\left.{ }^{\circ} \mathrm{C}\right)$ as:

$e_{s}=6.11 \times e^{\frac{17.62 \times T}{243.04+T}}$

As discussed in Sect. 1, the rate of change of extreme precipitation intensities is associated with that of saturation vapor pressure. Thus, extreme precipitation intensities can vary exponentially with temperature (which was also seen in the results of our study). Assuming that the denominator of the exponent term of Eq. (1) depends weakly on T for which saturation water vapor pressure varies exponentially with temperature, $e_{\mathrm{s}}$ in Eq. (1) as precipitation $(\mathrm{P})$ and the exponent term of Eq. (1) as constant ( $\alpha$ ) times T, we can calculate

$P=A e^{\alpha T}, \quad$ where $A$ is some constant

Taking two states of precipitation as $\mathrm{P}_{1}$ and $\mathrm{P}_{2}$ at temperatures $T_{1}$ and $T_{2}$, respectively, Eq. (2) can be written as:

$P_{1}=A e^{\alpha T_{1}}$ and $P_{2}=A e^{\alpha T_{2}}$

$\Rightarrow \frac{P_{2}}{P_{1}}=e^{\alpha\left(T_{2}-T_{1}\right)}$

Expanding $\mathrm{e}^{\alpha}$ and neglecting higher degree terms, we can write Eq. (3) as:

$P_{2}=P_{1}(1+\alpha)^{\Delta T}$

where $\Delta \mathrm{T}=\mathrm{T}_{2}-\mathrm{T}_{1}$ is the change in temperature and $\alpha$ is the rate of change of extreme precipitation intensities, which is $\sim 0.07$ in the case of CC.

Researchers (Lenderink and van Meijgaard 2008, 2010; Hardwick et al. 2010) have recently used Eq. (4) to obtain the rate $(\alpha)$ over their areas of study. To obtain the rate, we applied least squares method to perform linear regression to the logarithms of precipitations, which is similar to an exponential curve that best fits Eq. (2). Thus, the rate obtained from this regression results in $1+\alpha$, as given in Eq. (4). This equation was applied to each percentile of precipitation intensity to compute the rate $(\alpha)$.

\section{Reproducibility of extreme precipitation linked to temperature simulated by multi-model ensemble experiments}

To investigate the relationship between extreme precipitation simulated by multi-model ensemble experiments with temperatures over Japan, the model bias and its dependence on temperature and precipitation from daily and monthly datasets in the current climate (1981-2000) were analyzed. The precipitation dependence on temperature (the CC relationship) and the uncertainty of the multi-model ensemble were also explored.

\subsection{Model bias}

The biases of RCMs were derived by comparing the results of three RCM ensemble simulations forced by JRA25 and APHRODITE. The biases in the individual RCM, as well as in the ensemble means of three RCMs, in reproducing the temperature and precipitation intensities over Japanese land only are illustrated in Fig. 2 (using monthly datasets) and Table 2 (using daily datasets). An analysis of the daily mean temperature has revealed that NHRCM has a warm bias of $0.6^{\circ} \mathrm{C}$ and WRF has a cold bias of $0.6^{\circ} \mathrm{C}$ (see Table 2). The analysis of the monthly mean temperature also resulted in a warm bias in NHRCM and cold bias in WRF, but NRAMS had both: a warm bias for lower temperatures and a cold bias for higher temperatures (see Fig. 2a). However, the ensemble temperature mean was closer to actual observation. Similarly, we found WRF and NHRCM had a wet bias of 0.9 and $0.4 \mathrm{~mm} /$ day from the daily mean precipitation, while NRAMS had a dry bias of $0.4 \mathrm{~mm} /$ day. Figure $2 \mathrm{~b}$ highlights the strong dry bias for higher precipitations with NRAMS. However, the precipitation from the ensemble mean of the three models was closer to actual observation. These characteristics of individual model biases agree with those documented in previous studies (Iizumi et al. 2011; Ishizaki et al. 2012; Tsunematsu et al. 2013) over Japan. Moreover, the simulated mean, variance, and standard deviation indicate that the individual model statistics closely aligned with actual observation (see Table 2). Our results also indicated that temperature biases in individual models were mostly temperature-dependent (see Fig. 2a). Linear fits in Fig. 2a indicate that NRAMS and NHRCM exhibit a cooling bias at higher temperatures while WRF exhibits a warming bias. However, precipitation biases were found to be loosely dependent on precipitation intensities, except for NRAMS (see Fig. 2b). Thus, these biases may have contributed to uncertainties in the study results. For instance, Boberg and Christensen (2012) pointed out that regional climate models share temperature-dependent biases. However, the bias in the multi-model ensemble mean in the present study has been found to be nearly independent of temperature.

\subsection{Precipitation dependence on temperature}

The precipitation dependence on temperature simulated by the multi-RCMs and multi-GCMs ensemble experiments was compared to observations. Different percentiles of daily precipitation intensities linked to temperature as 
Fig. 2 Temperature (a) and precipitation (b) dependent model biases computed from monthly dataset. The lines in the figures indicate the linear fits to model biases
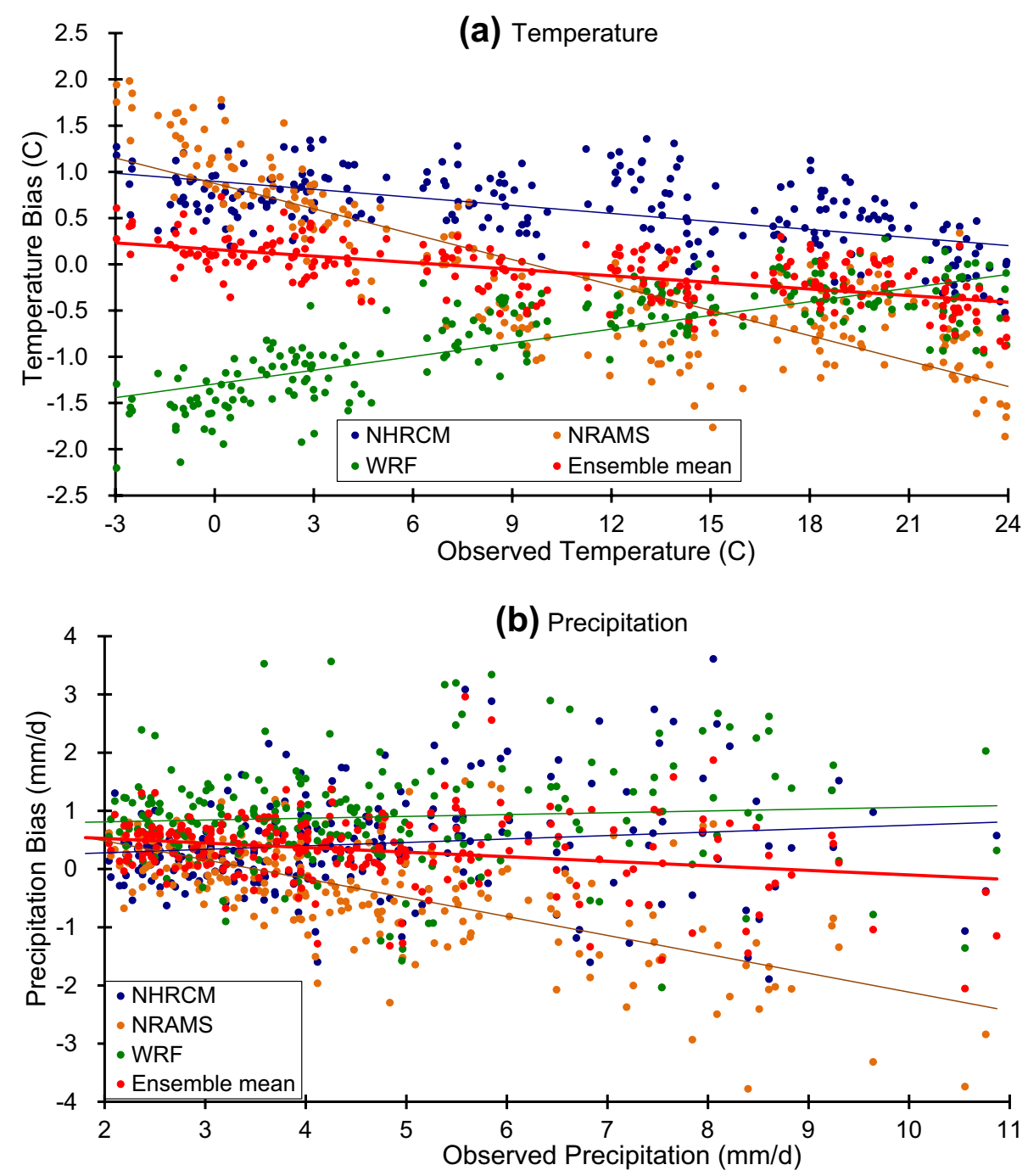

Table 2 Statistics from observation and each individual model. STD stands for standard deviation

\begin{tabular}{lrrll}
\hline & Mean & Bias & Variance & STD \\
\hline $\begin{array}{l}\text { Daily } \\
\text { Temperature (in }{ }^{\circ} \mathrm{C} \text { ) }\end{array}$ & & & & \\
$\quad$ Observation & 10.9 & & 73.1 & 8.6 \\
NHRCM & 11.5 & 0.6 & 70.3 & 8.4 \\
NRAMS & 10.8 & -0.1 & 61.2 & 7.8 \\
WRF & 10.3 & -0.6 & 80.6 & 9.0 \\
Ensemble mean & 10.9 & -0.0 & & \\
Precipitation (in mm/day) & & & & \\
Observation & 4.6 & & 35.8 & 6.0 \\
NHRCM & 5.0 & 0.4 & 43.4 & 6.6 \\
NRAMS & 4.2 & -0.4 & 23.3 & 4.8 \\
WRF & 5.5 & 0.9 & 42.6 & 6.5 \\
Ensemble mean & 4.9 & 0.3 & & \\
\hline
\end{tabular}

computed from the three RCM ensemble experiments forced by JRA25, individual GCM and multi-GCMs, and those of from APHRODITE are highlighted in Fig. 3. The dependence of extreme precipitations on $2 \mathrm{~m}$ air temperature from ensemble experiments of all three RCMs forced by JRA25 and each individual GCM are shown in Fig. 3a-d. The precipitation dependence on temperature from ensemble experiments of each individual RCM forced by multi-GCMs are presented in Fig. 3e-g. The 99th percentile of precipitation intensities from all ensemble members is shown in Fig. $3 \mathrm{~h}$. Solid lines (with filled circles) represent the extreme precipitation events from observation and dashed lines (with open circles) represent those from the multi-model ensemble mean of the RCMs/GCMs. Thin lines in Fig. 3a-g represent individual RCM (GCM) [solid lines for NHRCM (CCSM4), long dashed lines for NRAMS (MIROC5) and dotted lines for WRF (MRI-CGCM3)]. The black dotted line is for reference purposes and was obtained from the $\mathrm{CC}$ relationship. Results indicated that the extreme precipitation linked to 


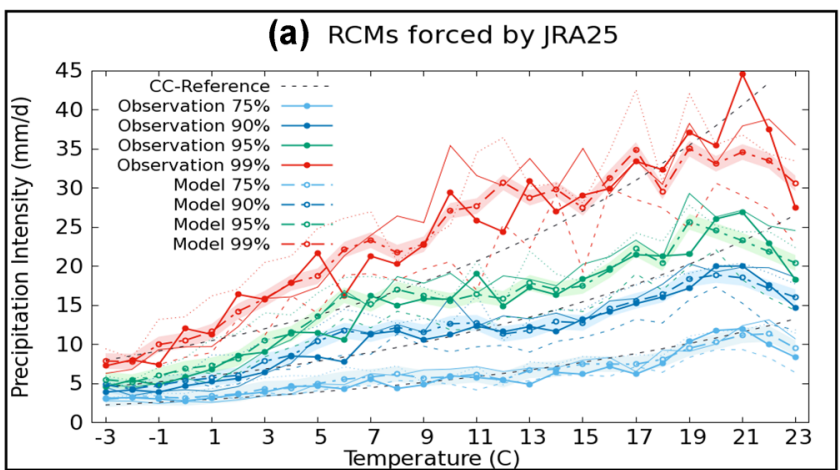

(b) RCMs forced by CCSM4

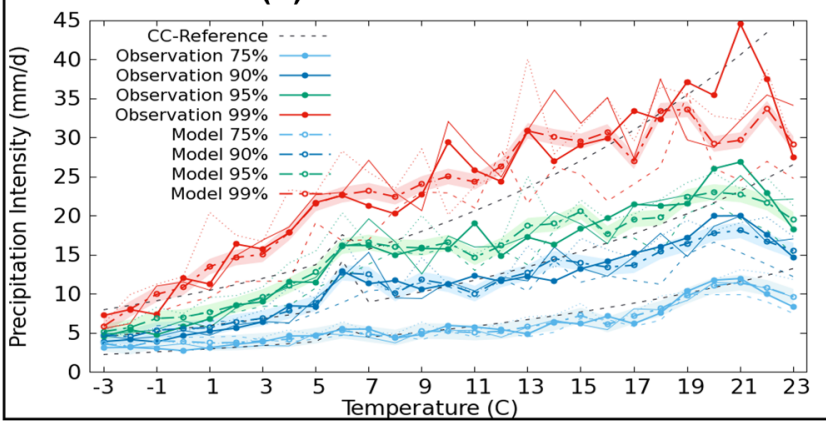

(c) RCMs forced by MIROC5
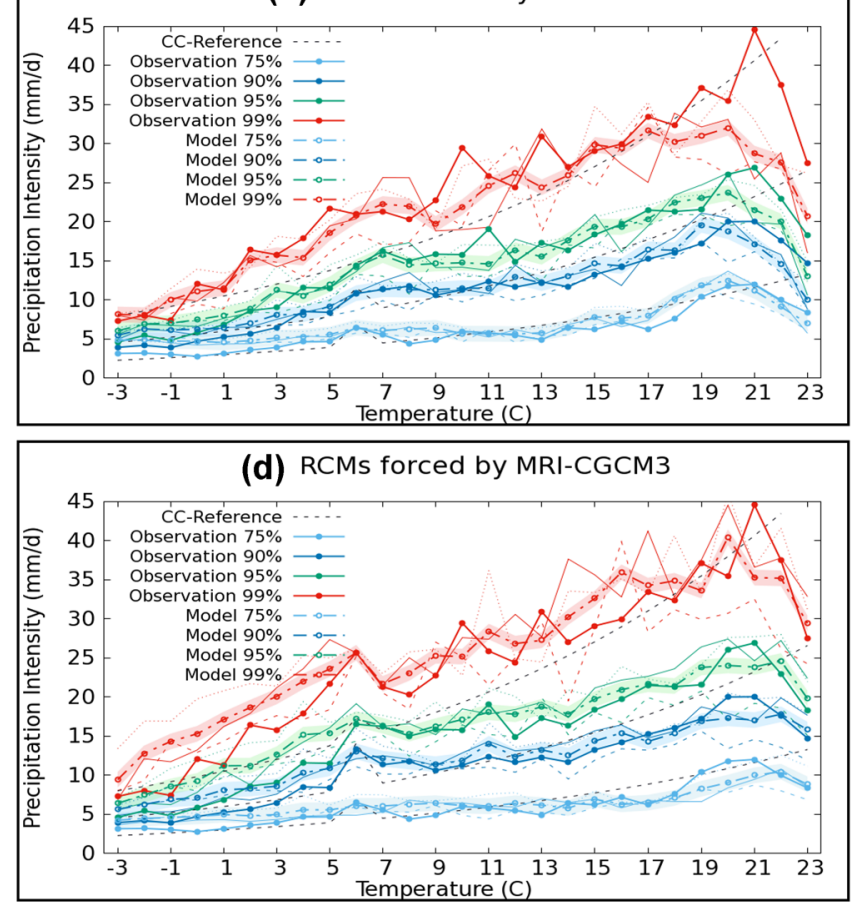

Fig. 3 Precipitation dependence on $2 \mathrm{~m}$ air temperature from ensemble experiments of three RCMs (NHRCM, NRAMS, and WRF) forced by JRA25 and three GCMs (CCSM4, MIROC5, and MRICGCM3) and compared with observation (APHRODITE) over Japan. Left panel shows the results of all three RCMs forced by a JRA25, b CCSM4, c MIROC5, and d MRI-CGCM3. Right panel shows the

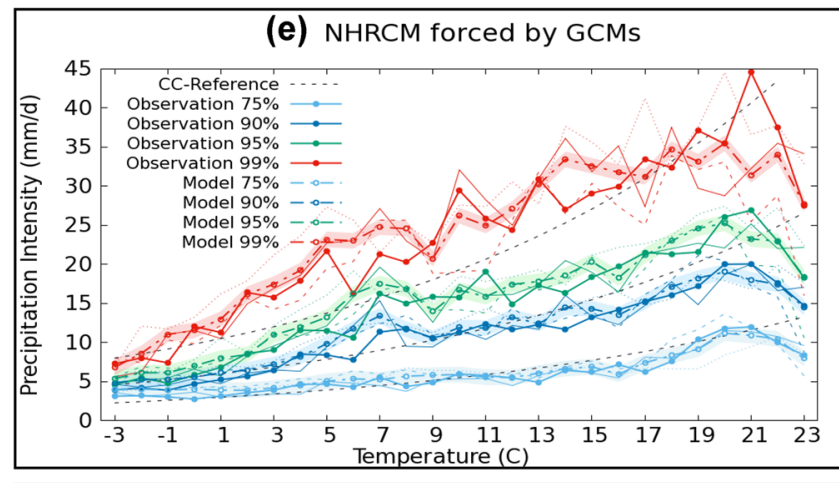

(f) NRAMS forced by GCMs
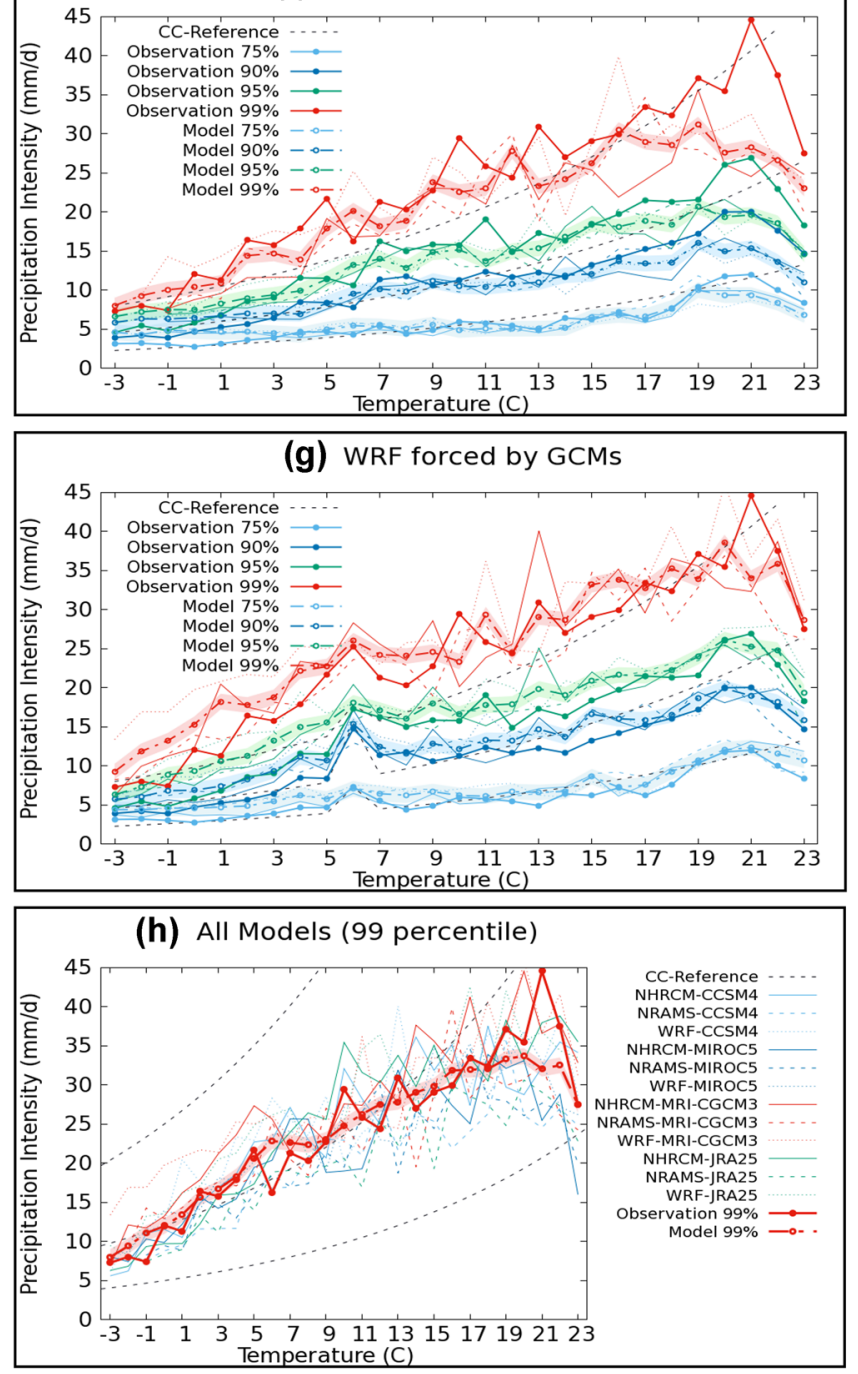

results of e NHRCM, f NARMS, g WRF driven by all three GCMs, and $\mathbf{h}$ 99th percentile of precipitation intensities from multi-model ensemble. Thin lines in $\mathbf{a}-\mathbf{g}$ represent individual RCM (GCM) [solid lines for NHRCM (CCSM4), long dashed lines for NRAMS (MIROC5) and dotted lines for WRF (MRI-CGCM3)]. Shaded region indicates $\pm 1 \mathrm{SD}$ 
temperature was in near agreement with observations in all cases. Intensity of extreme precipitation events has peaks around $19-22{ }^{\circ} \mathrm{C}$ for all percentiles of observation. The multi-model ensemble also reproduced the peaks. Higher extreme precipitations (95th and 99th percentiles) are underestimated for higher temperatures, ranging from 20 to $22^{\circ} \mathrm{C}$, and show a relatively weaker peak. This result coincides with previous research over Japan used these RCMs driven by the MIROC3.2 (Nayak and Dairaku 2016). All of the three RCMs also show similar characteristics (shown as thin different lines in Fig. 3h), with some uncertainties, except NHRCM forced by MRI-CGCM3 (Fig. 3d, h). Closer looks of the relationship of extreme precipitation with temperature in each individual RCM or GCM group (in Fig. 3) indicates that none of the individual model is outperforming the extreme precipitations at all temperatures. For instance, NHRCM is good at lower temperatures (Fig. 3e); WRF is good at higher temperatures (Fig. 3g); and NRAMS is good at lower temperatures of lower percentiles (Fig. 3f). Similarly, we found that RCMs can reproduce the extreme precipitations linked to temperature well for the temperatures roughly below $19{ }^{\circ} \mathrm{C}$ when forced by JRA25, CCSM 4 and MIROC5 (Fig. 3a-c). The RCMs can reproduce the relationship well for higher temperature (above $\sim 17^{\circ} \mathrm{C}$ ) when forced by MRI-CGCM3 (Fig. 3d). These indicate that the extreme precipitation intensities linked to temperature are strongly influenced by individual ensemble experiment. However, the extreme precipitations linked to temperature in the ensemble mean of three RCMs forced by JRA25 and three GCMs follow the observation more closely compared to that in each individual experiment (Fig. 3h). This implies that the multi-model ensemble approach yields superior results compared to an individual experiment (IPCC 2007; Kirtman et al. 2014).

To investigate the reproducibility of the results in the multi-model ensemble experiments, the different percentiles of daily precipitation intensities linked to temperature from the multi-RCMs ensemble experiments forced by the multi-GCMs were also compared with observations (see Fig. 4). The dependence of daily precipitation on temperature from the ensemble average also showed an agreement with observations, while higher extreme precipitation (90th, 95th, and 99th percentiles) were underestimated for higher temperatures. The multi-model ensemble forced by multiGCMs also reproduced peaks.

The comparison of extreme precipitation, forced by multi-GCMs and JRA25, with the CC relationship indicates that the higher percentiles (90th, 95th, 99th) of precipitation intensities exhibit super-CC scaling at temperatures below $\sim 10^{\circ} \mathrm{C}$ and all percentiles follow a sub-CC scaling for temperatures roughly above $10^{\circ} \mathrm{C}$. Similar relationship over Japan was also reported in the previous research forced by the MIROC3.2 (Nayak and Dairaku 2016). The extreme

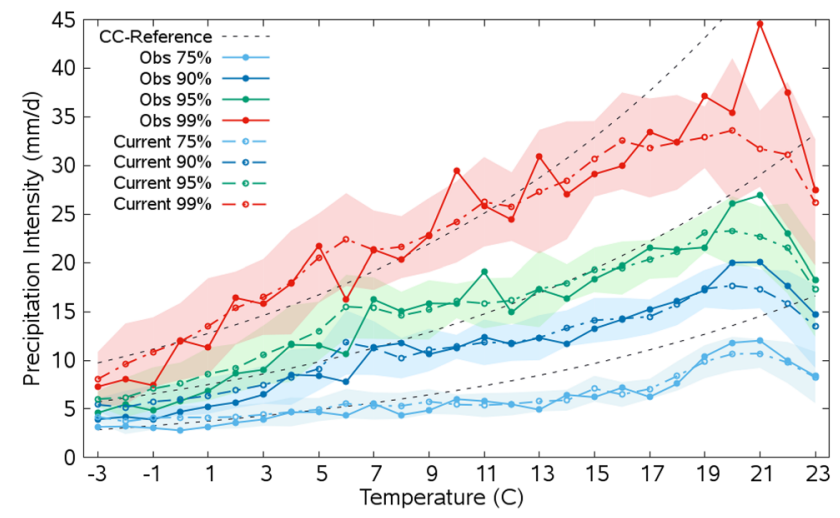

Fig. 4 Precipitation dependence from the ensemble mean of nine members forced by multi-GCMs and observation (Obs) with uncertainty in the current climate. Shaded region indicates the mean \pm standard deviation

daily precipitations over different regions of Europe, Japan, and Australia also show sub-CC scaling behavior at higher temperatures (e.g. Berg et al. 2009; Hardwick et al. 2010; Utsumi et al. 2011), but do not show the super-CC at lower temperatures. However, we find super-CC scaling at lower temperatures over Japan which agrees with previous studies by Lenderink and van Meijgaard $(2008,2010)$ conducted at De Bilt (Netherlands), Ukkel (Belgium), Barn (Basel), and Zurich (Switzerland). The reason of showing super-CC at lower temperatures over Japan could be associated with seasonality and regionality. Because the lower temperatures over Japan mainly correspond to winter season during which the precipitation is determined by extratropical disturbances and cold outbreaks from Siberian Highs. This may bring significant amounts of precipitation during winter over Japan and may likely exhibit a super-CC at lower temperatures. An increasing pattern in precipitation intensities was noticed for temperatures below $\sim 20^{\circ} \mathrm{C}$ and a further increase in temperature caused a decrease in precipitation intensity. Hardwick et al. (2010) and Utsumi et al. (2011) also reported similar peaks in observed precipitation over the interior of Australia and some islands of Japan, respectively.

To further investigate the uncertainties in these results, we analyzed the mean \pm standard deviation using the results of all the ensemble experiments. These are shown as shaded region for every percentile in Fig. 4. These results confirmed that the range of uncertainty varies with the percentile of extreme events and greater uncertainty correlates to a higher percentile of extreme precipitation (by $1-5 \mathrm{~mm} /$ day for lower percentiles (75th, 90th, and 95th) and by $2-7.5 \mathrm{~mm} /$ day for the 99th percentile). However, observations are almost within the uncertainty range of one standard deviation. 


\section{Projected future changes in precipitation dependence on temperature}

The frequency distribution of precipitation intensities and temperature over Japan are discussed in the framework of two climate periods (1981-2000 and 2081-2100). The change rates of intensities of mean and extreme precipitation are also explored.

\subsection{Projected changes of frequency distribution of precipitation and temperature}

The frequency distribution of precipitation and temperature from multi-model ensemble downscaling experiments (see Fig. 5) indicates that precipitation intensity as well as temperature are projected to increase in the climate scenarios as compared to the current climate. The frequency of precipitation is defined as the number of days in the bins of $5 \mathrm{~mm} /$ day and the frequency of $2 \mathrm{~m}$ air temperature refers to the number of days in the bins of $1{ }^{\circ} \mathrm{C}$. A significant precipitation increase is projected for climate scenarios, in which stronger precipitation intensities measure roughly above $15 \mathrm{~mm} / \mathrm{d}$, but a decrease in precipitation is projected within the range of $10-15 \mathrm{~mm} /$ day (see Fig. 5a; Table 3). The $2 \mathrm{~m}$ air temperature is projected to increase by about $2{ }^{\circ} \mathrm{C}$ in climate
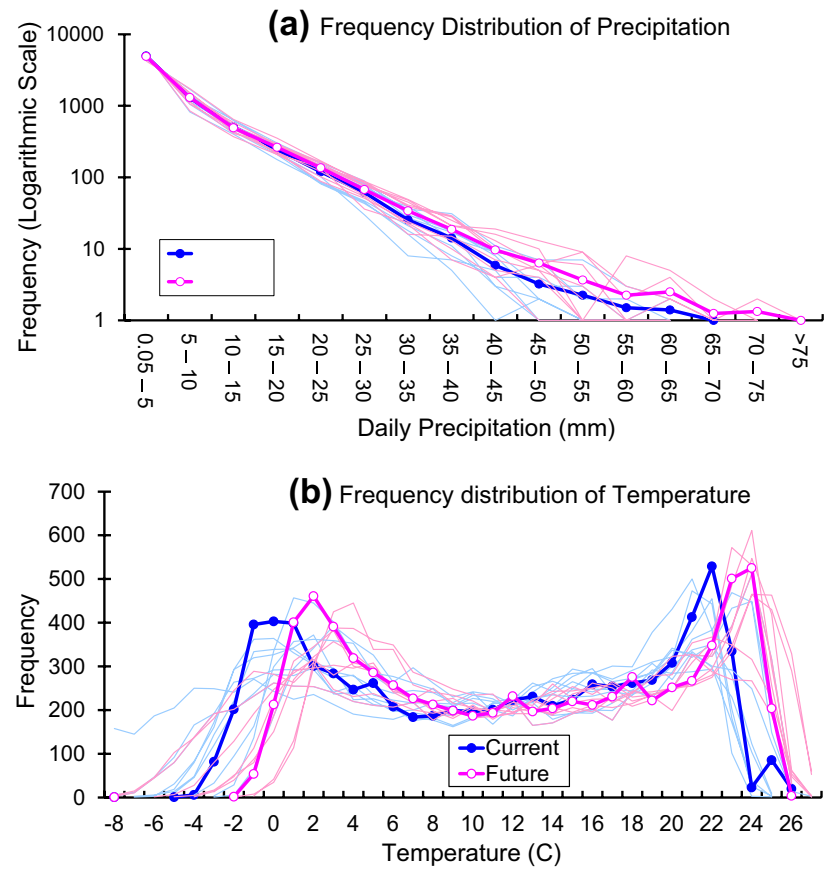

Fig. 5 Frequency distribution of a precipitation and $\mathbf{b} 2 \mathrm{~m}$ air temperature from current (1981-2000) and future (2081-2100) climate scenarios. Solid lines represent the frequency from the ensemble average and thin lines represent those from individual ensemble members. The frequency is defined as a the number of precipitation events in the bins of $5 \mathrm{~mm} / \mathrm{d}$ and $\mathbf{b}$ daily temperature in the bins of $1{ }^{\circ} \mathrm{C}$
Table 3 Increase or decrease of precipitation frequency and amount $(\%)$ in the future climate with respect to the current climate from multi-model ensemble average

\begin{tabular}{lcc}
\hline $\begin{array}{l}\text { Precipitation bin } \\
(\mathrm{mm} / \text { day) }\end{array}$ & $\begin{array}{l}\text { Change of frequency } \\
\text { (future-current) }\end{array}$ & $\begin{array}{l}\text { Change of precipi- } \\
\text { tation amount }(\%)\end{array}$ \\
\hline $0.05-5$ & -83 & -2 \\
$5-10$ & 13 & 1 \\
$10-15$ & -14 & -3 \\
$15-20$ & 19 & 8 \\
$20-25$ & 16 & 14 \\
$25-30$ & 6 & 10 \\
$30-35$ & 9 & 34 \\
$35-40$ & 5 & 32 \\
$40-45$ & 4 & 64 \\
$45-50$ & 3 & 97 \\
$>50$ & 5 & 57 \\
\hline
\end{tabular}

We calculated the change of precipitation amount by (future change/ current) $\times 100$

scenarios (Fig. 5b). The frequencies of lower $\left(<1{ }^{\circ} \mathrm{C}\right)$ and higher $\left(>19^{\circ} \mathrm{C}\right.$ and $\left.<23{ }^{\circ} \mathrm{C}\right)$ temperatures are projected to significantly decrease in climate scenarios. Warm days (temperature $>23{ }^{\circ} \mathrm{C}$ ) are projected to increase in the future climate and the cold days (temperatures $>1{ }^{\circ} \mathrm{C}$ and $<10^{\circ} \mathrm{C}$ ) are also projected to increase compared to the current climate. Previous multi-model ensemble downscaling research forced by MIROC3.2 with an SRES A1B scenario also projected the increase in precipitation intensities over Japan in the climate scenarios (e.g., Tsunematsu et al. 2013). To account for the uncertainty of the multi-model ensemble, we plotted the frequency distribution of precipitation and temperature for each model. These are shown as thin lines in Fig. 5. We also counted the number of models showing positive/negative changes of precipitation intensities and temperatures in the future climate compared to the current climate. Most of the models show that the frequency of higher precipitation intensities ( $>15 \mathrm{~mm} /$ day) as well as higher temperatures $\left(>23{ }^{\circ} \mathrm{C}\right.$ ) is projected to increase in the future climate (see Table 4). A low frequency of higher precipitation is found in NRAMS compared to NHRCM and WRF, as a result of a strong dry bias in NRAMS for higher precipitation, as discussed in Sect. 3.1.

In the next Sect. 4.2, we analyze the projected change rate of mean precipitation intensities per mean change in air temperature.

\subsection{Projected mean precipitation change per mean change in air temperature}

We first discussed the change rate of the mean precipitation (considering wet days only) change in two climate periods 
Table 4 Number of models showing increase $(+)$ or decrease $(-)$ of frequency of each precipitation (Prec.) and temperature (Temp.) bin in the future climate compared to the current climate

\begin{tabular}{llllllllllll}
\hline $\begin{array}{l}\text { Prec. bin } \\
(\mathrm{mm} / \text { day })\end{array}$ & + & - & Temp. bin $\left({ }^{\circ} \mathrm{C}\right)$ & + & - & Temp. bin $\left({ }^{\circ} \mathrm{C}\right)$ & + & - & Temp. bin $\left({ }^{\circ} \mathrm{C}\right)$ & + & - \\
\hline $0.05-5$ & 3 & 6 & $<-4$ & & 4 & 6 to 7 & 9 & 0 & 17 to 18 & 2 & 7 \\
$5-10$ & 5 & 4 & -4 to -3 & & 5 & 7 to 8 & 8 & 1 & 18 to 19 & 9 & 0 \\
$10-15$ & 2 & 7 & -3 to -2 & & 8 & 8 to 9 & 9 & 0 & 19 to 20 & 1 & 8 \\
$15-20$ & 7 & 2 & -2 to -1 & 1 & 7 & 9 to 10 & 8 & 1 & 20 to 21 & 2 & 7 \\
$20-25$ & 8 & 1 & -1 to 0 & 1 & 8 & 10 to 11 & 3 & 6 & 21 to 22 & 2 & 7 \\
$25-30$ & 6 & 3 & 0 to 1 & 1 & 8 & 11 to 12 & 3 & 6 & 22 to 23 & 2 & 7 \\
$30-35$ & 8 & 1 & 1 to 2 & 4 & 5 & 12 to 13 & 2 & 7 & 23 to 24 & 7 & 2 \\
$35-40$ & 8 & 1 & 2 to 3 & 5 & 4 & 13 to 14 & 2 & 7 & 24 to 25 & 9 & 0 \\
$40-45$ & 8 & 1 & 3 to 4 & 8 & 1 & 14 to 15 & 4 & 5 & 25 to 26 & 9 & 0 \\
$45-50$ & 8 & 1 & 4 to 5 & 9 & 0 & 15 to 16 & 2 & 7 & 26 to 27 & 9 & 0 \\
$>50$ & 8 & & 5 to 6 & 9 & 0 & 16 to 17 & 1 & 8 & $>27$ & 7 & \\
\hline
\end{tabular}

A blank box indicates that other models could not reproduce the precipitation or temperature in the respective bin

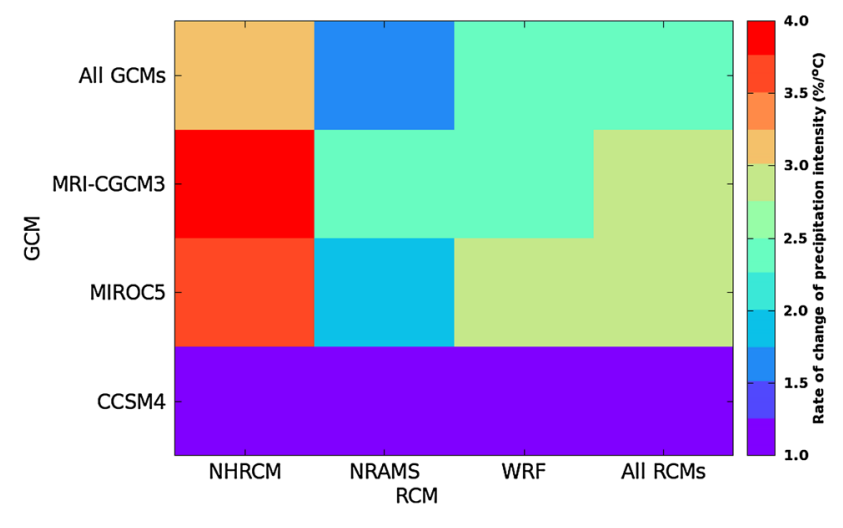

Fig. 6 Future change rate of the mean precipitation [considering wet days only ( $\geq 0.05 \mathrm{~mm} /$ day)] change in two climate periods with respect to the mean temperature change

with respect to the mean temperature change by using the following formula.

Change rate $=\frac{P_{\text {future_mean }}-P_{\text {present_mean }}}{P_{\text {present_mean }}\left(T_{\text {future_mean }}-T_{\text {present_mean }}\right)} \times 100$

where $P_{x}$ is the mean precipitation intensities of the wet days during 1981-2000 for current climate (2081-2100 for future climate) and $T_{x}$ is the mean temperature of those wet days.

Using the above Eq. (5) we analyzed the change rates in the mean precipitation intensities from each individual model and single RCM/GCM group. Figure 6 indicates that the change rate in the mean precipitation intensities is $\sim 1 \% /{ }^{\circ} \mathrm{C}$ in each $\mathrm{RCM}$ driven by CCSM4, while it is in the range of $1.5-3.5 \% /{ }^{\circ} \mathrm{C}$ in each RCM driven by MIROC5 and $2.5-4 \% /{ }^{\circ} \mathrm{C}$ in each RCM driven by MRI-CGM3. The change rate in the mean precipitation intensities is found higher in NHRCM compared to NRAMS and WRF. This implies that the change in precipitation intensities with respect to the change in air temperature is varying from RCM to RCM and GCM to GCM. The multi-model ensemble mean of the future change rates is found to be $2.4 \% /{ }^{\circ} \mathrm{C}$.

We next discuss the rates of change of extreme precipitations linked to temperature in two climate periods and their connection to $\mathrm{CC}$ relationship.

\subsection{Projected changes of extreme precipitation dependence on temperature}

The dependence of extreme precipitation on temperature for the current climate and the future climate, as computed from each nine-member ensemble of experiments by three RCMs driven by three GCMs, is highlighted in Fig. 7. The dependence of extreme precipitations on temperature of three RCMs forced by CCSM4, MIROC5, MRI-CGCM3, and multi-GCMs are shown in Fig. 7a-d. The dependence of extreme precipitations on temperature from each individual RCM forced by multi-GCMs are presented in Fig. 7e-g. The 99th percentile of precipitation intensities in current and future climate from all ensemble members is shown in Fig. $7 \mathrm{~h}$. The results for current climate in Fig. $7 \mathrm{~d}$ are same as those in Fig. 4. Similar to the results discussed in Sect. 3.2, all percentiles of extreme precipitation exhibit similar subCC scaling for temperatures above $10{ }^{\circ} \mathrm{C}$ and peak at the $19-23{ }^{\circ} \mathrm{C}$ range in both current and projected future climates. The higher percentiles (95th and 99th) show a super$\mathrm{CC}$ scaling for temperatures below $10^{\circ} \mathrm{C}$. All RCM or GCM groups also show similar CC-scaling. The extreme precipitation intensities (all percentiles) in each group are significantly increased in climate scenarios at higher temperatures except the lower percentiles in the simulations with multiRCMs forced by MRI-CGCM3 (Fig. 7a-g). Each individual model shows large uncertainties in reproducing the future 

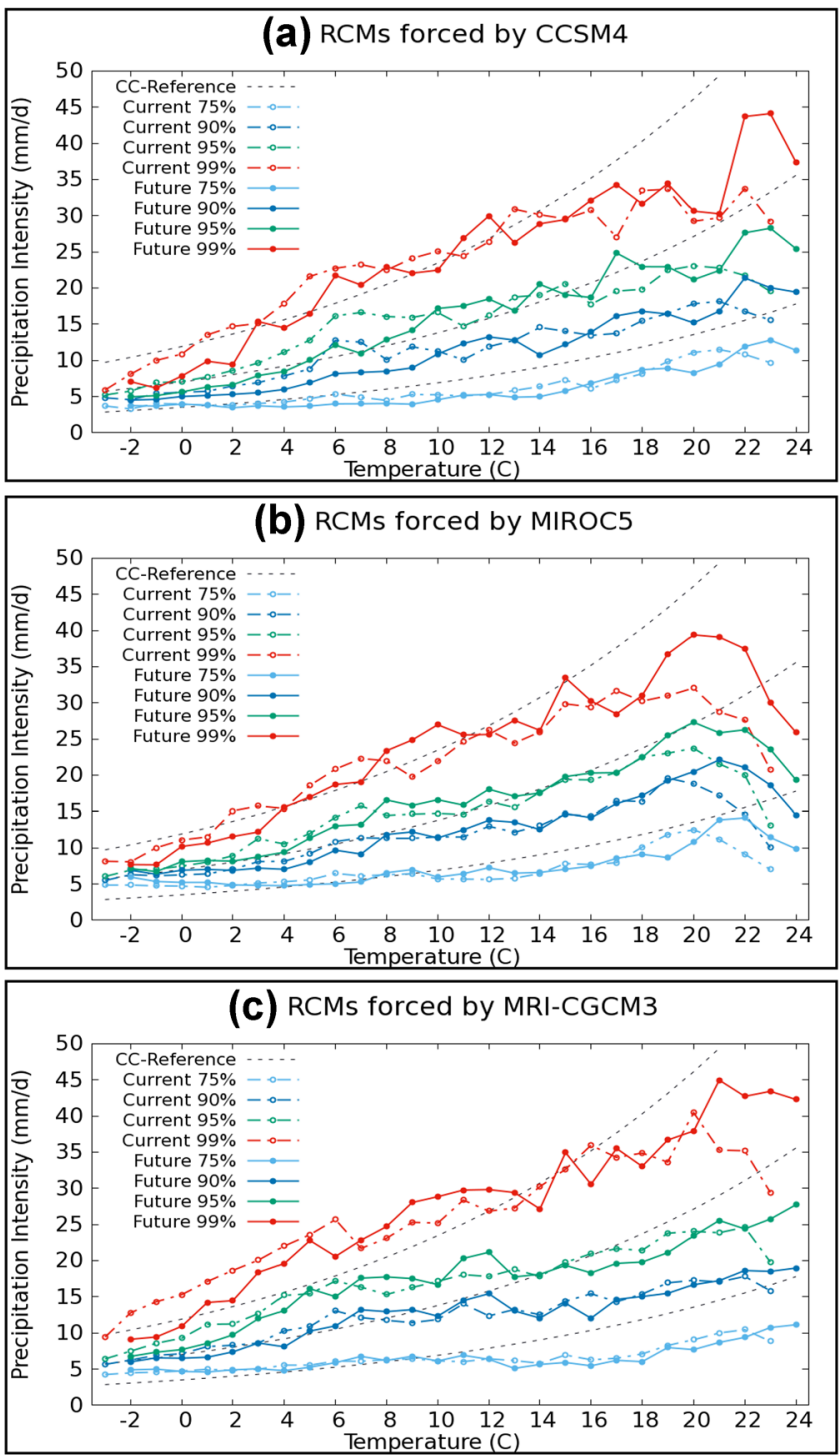

(d) RCMs forced by GCMs

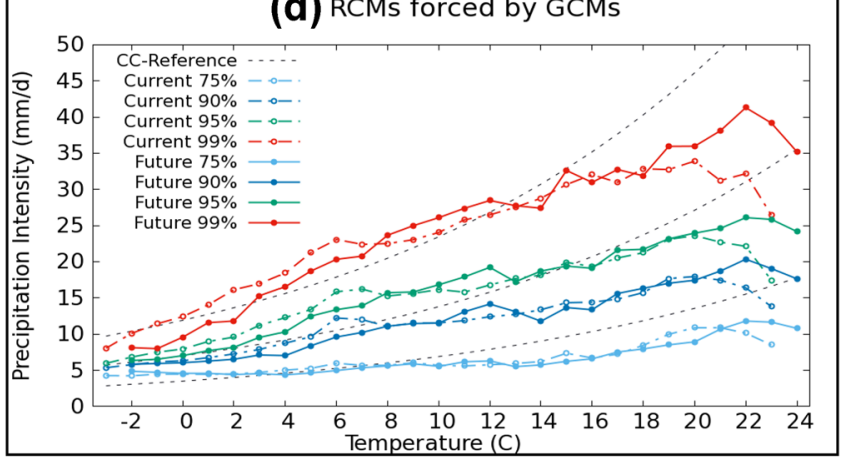

Fig. 7 Daily precipitation dependence on daily mean temperature from multi-model ensemble downscaling experiments of three RCMs (NHRCM, NRAMS, WRF) forced by three GCMs (CCSM4, MIROC5, MRI-CGCM3) for the current (1981-2000) and future (2081-2100, RCP4.5) climate scenarios over Japan. Left panel shows
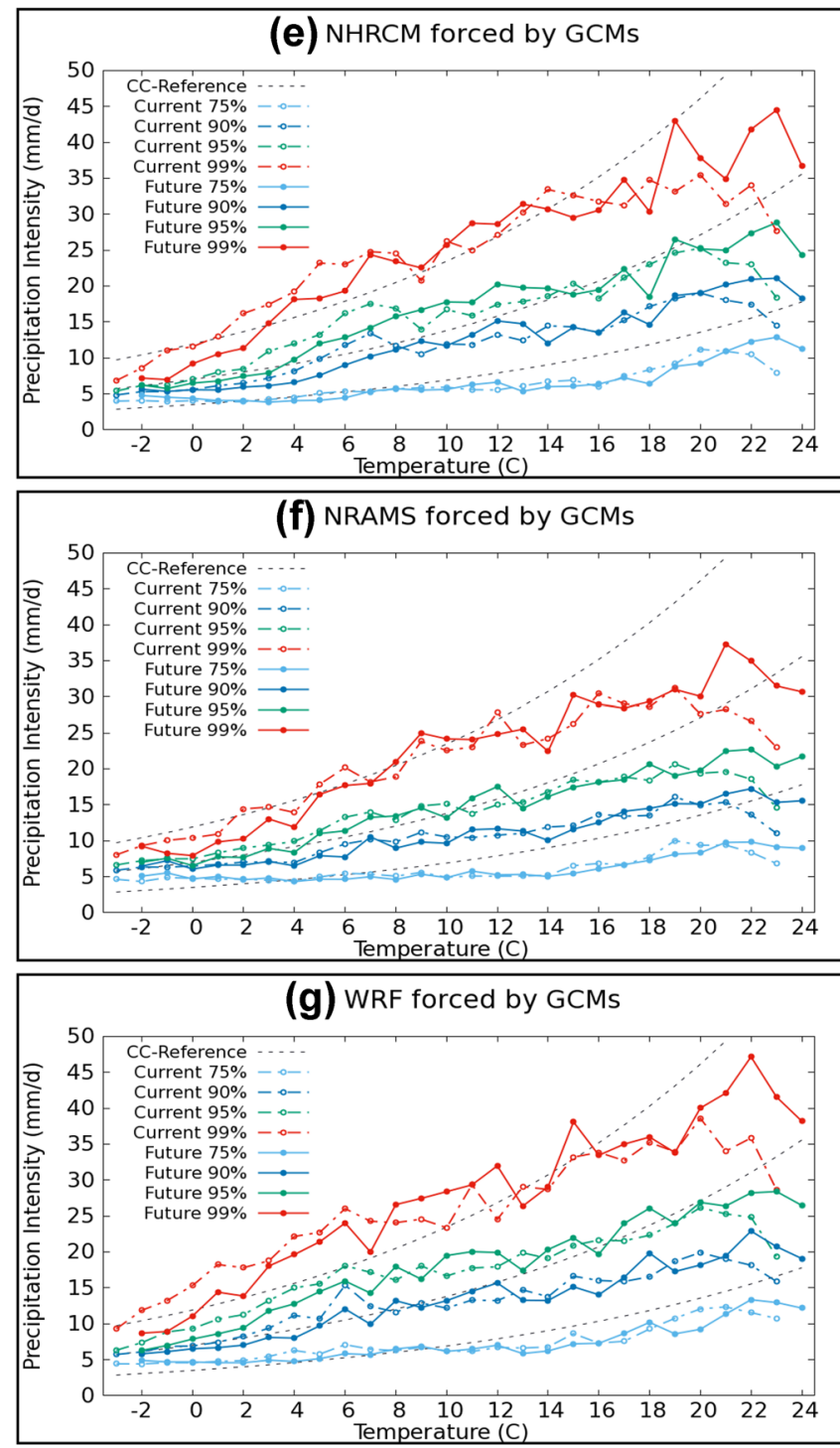

(h) All Models (99 percentile)

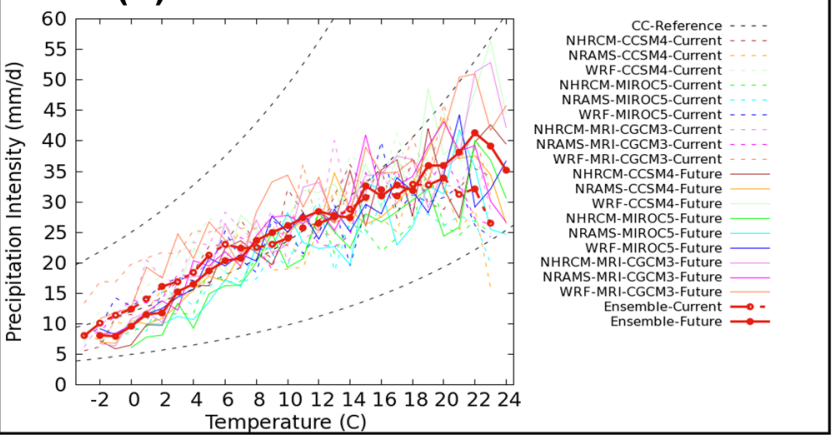

the results of all three RCMs forced by a CCSM4, b MIROC5, c MRI-CGCM3, and d all three GCMs. Right panel shows the results of $\mathbf{e}$ NHRCM, f NARMS, $\mathbf{g}$ WRF driven by all three GCMs, and $\mathbf{h}$ 99th percentile of precipitation intensities from multi-model ensemble. The results for current climate in $\mathbf{d}$ are same as those in Fig. 4 
changes of extreme precipitation (Fig. $7 \mathrm{~h}$ ). However, the higher percentiles in the multi-model ensemble experiments confirm that extreme precipitation intensities (99th percentile) are projected to significantly increase by $5 \mathrm{~mm} /$ day in climate scenarios for temperatures roughly above $21{ }^{\circ} \mathrm{C}$. Extreme precipitation intensities increase with temperature up to $22{ }^{\circ} \mathrm{C}$ in the future climate, while the peak is $20^{\circ} \mathrm{C}$ for the current climate. The warming shift of about $2{ }^{\circ} \mathrm{C}$ is consistent with the projected $2{ }^{\circ} \mathrm{C}$ rise in temperature in the climate scenarios (see Fig. 5b). Extreme precipitation can vary exponentially with temperature, according to Eq. (2) in Sect. 2. This exponential variation partially supports the projected increase of stronger extreme precipitation with the increase of temperature in climate scenarios.

In the subsequent Sect. 4.4, we discuss the rates of extreme precipitation intensities linked to temperature in two climate periods.

\subsection{Projected rate of extreme precipitation intensities linked to temperature}

We calculated the rate of the dependence of extreme precipitation intensities $(\alpha)$ using the least squares methods as described in Sect. 2 and its variation of different precipitation percentiles (for instance, 75th, 85th, 90th, 95th, 97th, and 99th) with different temperature ranges in current as well as climate scenarios (Fig. $8 \mathrm{a}-\mathrm{c}$ ). The rates $(\alpha)$ of different precipitation percentiles for all temperatures considered are shown in Fig. 8a; those using only temperatures above $20{ }^{\circ} \mathrm{C}$ are shown in Fig. $8 \mathrm{~b}$; and those using only temperatures below $19{ }^{\circ} \mathrm{C}$ are shown in Fig. 8c. The rates $(\alpha)$ of all the percentiles are in the range of $3-5 \% /{ }^{\circ} \mathrm{C}$ (sub-CC) in the current climate, as illustrated by a bold line with filled circle in Fig. 8a. These rates $(\alpha)$ are projected to increase to $4-6 \% /{ }^{\circ} \mathrm{C}$ in the future climate (as shown by the bold line with open circle). This result is consistent with the previous research over Japan (differences of the ranges are around $0.5 \% /{ }^{\circ} \mathrm{C}$ ) conducted by Nayak and Dairaku (2016) with three RCMs (NHRCM, NRAMS, WRF) driven by one GCM (MIROC3.2) under the SRES A1B scenario. Extreme precipitations of higher percentiles are projected to have higher increase rates in climate scenarios. The rates $(\alpha)$ of all individual models are also projected to increase in the future climate (as shown in thin lines in Fig. 8a). All models follow sub-CC in current as well as climate scenarios. We counted the number of models showing positive/negative changes of rates $(\alpha)$ of different extreme precipitation intensities in the future climate compared to the current climate (see Table 5). The table highlights that all models indicate increasing change rates $(\alpha)$ of higher percentiles (95th, 97th, $99 \mathrm{th})$ in the future projection. Figure $8 \mathrm{~b}$ indicates decreasing (increasing) rates $(\alpha)$ in the range of $-7-9 \% /{ }^{\circ} \mathrm{C}\left(+0-4 \% /{ }^{\circ} \mathrm{C}\right)$ for temperature above $20^{\circ} \mathrm{C}$ in the current (future) climate.
The rates $(\alpha)$ of higher percentiles (above $95 \%$ ) for temperature below $19{ }^{\circ} \mathrm{C}$ are about $6 \% /{ }^{\circ} \mathrm{C}$. Those are projected to increase to $7 \% /{ }^{\circ} \mathrm{C}$ (CC-scaling) in the future climate (Fig. 8c). The rates $(\alpha)$ are projected to significantly increase in climate scenarios due to the shift of the peak associated with the projected temperature increase (Figs. 5b, 7).

The change rates shown in Fig. 6 are just the change rates of mean precipitation change per mean air temperature change (Sect. 4.2). That is not same as the rates estimated by CC-relationship as discussed in this section. The two analyses (i.e., Fig. 6 in Sect. 4.2 and Fig. 8 in Sect. 4.4) have different meanings. Figure 6 highlights the rate of projected mean precipitation change of all the wet-day events per projected mean temperature change. Figure 8 shows the rates (CC-scaling $\alpha$ ) of extreme precipitations linked to temperature in each current and future climate.

\section{Discussions}

Our discussion is twofold. First, we focus on the decrease of precipitation intensity at higher temperatures; and second, we discuss on the future increase of extreme precipitation intensities linked to temperature.

\subsection{Decrease of precipitation intensity at higher temperatures}

Our overall results indicate that the extreme precipitations linked to temperature over Japan mostly follow the CC relationship up to a certain degree (for instance $19-22{ }^{\circ} \mathrm{C}$ ) and a further increase in temperature causes a decrease in precipitation intensity over Japan. These results were found in observation as well as in multi-model ensemble downscaling experiments. Moreover, similar results have been achieved in a multitude of studies conducted over various regions of the world (e.g., Lenderink and Meijgaard 2008; Berg et al. 2009; Hardwick et al. 2010). Increase of extreme precipitations with rise in temperature is plausible, according to $\mathrm{CC}$ equation, but the question is why precipitation intensities stopped increasing at higher temperatures. Certainly at higher temperatures, water vapor increases more slowly, while larger amounts of atmospheric moisture are required to drive the atmosphere to saturation (Berg et al. 2009). As a result, formation of cloud water decreases as moisture is required to maintain the precipitation-temperature relationship. Hardwick et al. (2010) also suggest that the amount of moisture that is available in the atmosphere is more important than the moisture holding capacity in the atmosphere. It is possible that oceans play a major role in supplying the moisture required for intense precipitation. During summer, i.e., at higher temperatures, the moisture parcel from oceans becomes sub-saturated due to warmer land surfaces. As a 
Fig. 8 Increased rate of extreme precipitation and its variation with increase in percentiles of precipitation a considering all the temperatures; b considering the temperatures above $20{ }^{\circ} \mathrm{C}$; $\mathbf{c}$ considering the temperatures below $19^{\circ} \mathrm{C}$. Thin lines represent the rate from each individual model
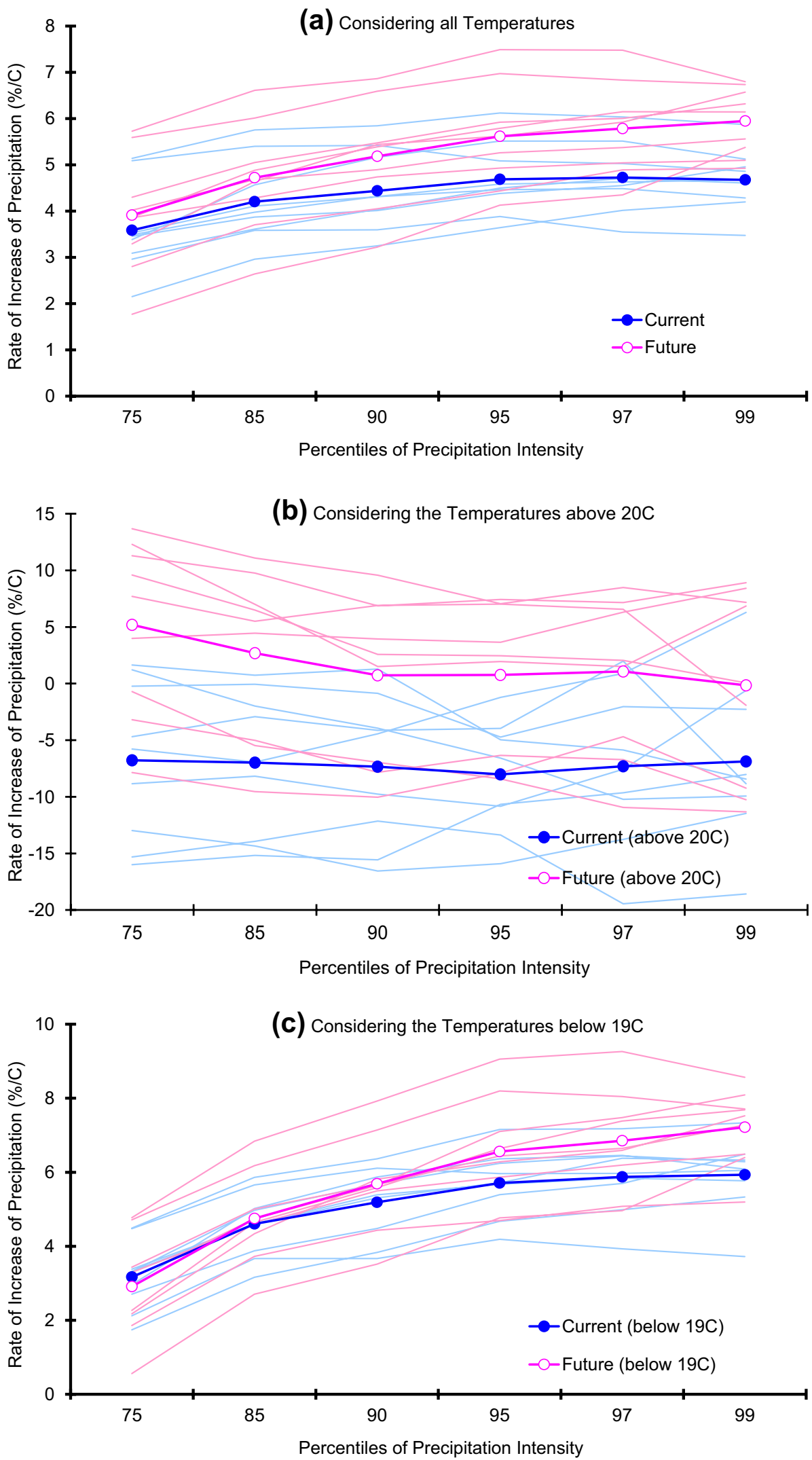
Table 5 Number of models showing positive (+) or negative (-) changes of rates $(\alpha)$ of extreme precipitation intensities in the future climate compared to the current climate

\begin{tabular}{lll}
\hline $\begin{array}{l}\text { Percentiles of precipitation } \\
\text { intensities }\end{array}$ & Positive change & $\begin{array}{l}\text { Negative } \\
\text { change }\end{array}$ \\
\hline 75 & 6 & 3 \\
85 & 8 & 1 \\
90 & 8 & 1 \\
95 & 9 & 0 \\
97 & 9 & 0 \\
99 & 9 & 0 \\
\hline
\end{tabular}

result, saturation gets suppressed and less precipitation is produced. Utsumi et al. (2011) highlighted that the saturation level of the atmosphere may be related to changes in the wet-event duration measured by the wet-time fraction. In their study, the decrease of extreme precipitation intensities at higher temperatures was associated with a steep decrease in the wet-time fraction over Kyushu and southern islands of Japan. Many other theories associated with precipitation dependence on temperature have been introduced by Westra et al. (2014).
To understand more about the mechanism that precipitation intensity decreases at higher temperatures, we analyzed the behaviors of cloud cover (Fig. 9), relative humidity at $2 \mathrm{~m}$ (Fig. 10), and latent heat fluxes (Fig. 11) over Japan land during extreme events in the current climate from ensemble experiments. The dependence patterns of cloud cover at higher temperatures are found to be similar to the precipitation dependence on temperature. The cloud cover for each extreme precipitation percentile decreases at higher temperatures (see Fig. 9). Relative humidity at $2 \mathrm{~m}$ is higher for stronger extreme precipitation. However, relative humidity decreases at higher temperatures during extreme events (95th, 99th percentiles) (Fig. 10). Latent heat flux increases at higher temperatures but the rate of increase begins to lower at temperatures above $16{ }^{\circ} \mathrm{C}$ (Fig. 11). This indicates relatively less water vapor supply for saturation at higher temperatures, which should cause less cloud formation and extreme precipitation. These results are consistent with research by Hardwick et al. (2010), in which less relative humidity at higher temperatures was observed over Australia. We extended the analysis to extreme precipitation dependence on dew point temperature rather than temperature (Fig. 12). As discussed in Sect. 3.2, similar peaks in
Fig. 9 Cloud cover (daily) as a function of daily mean temperature during extreme precipitation events for the current climate computed from ensemble experiments

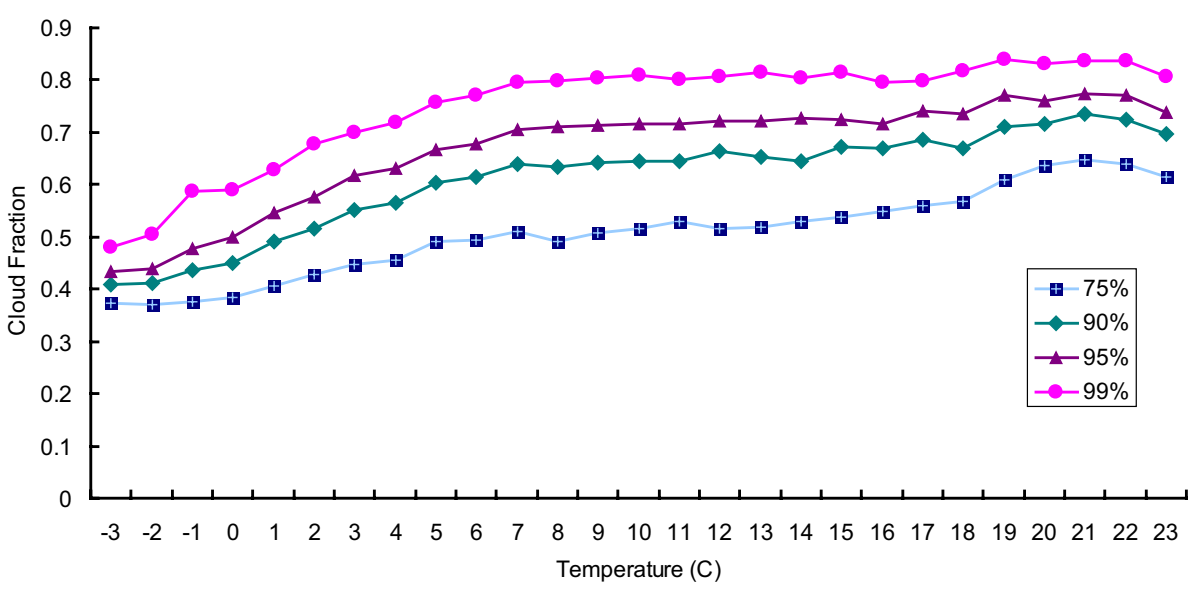

Fig. 10 Same as Fig. 8, but with relative humidity at $2 \mathrm{~m}$

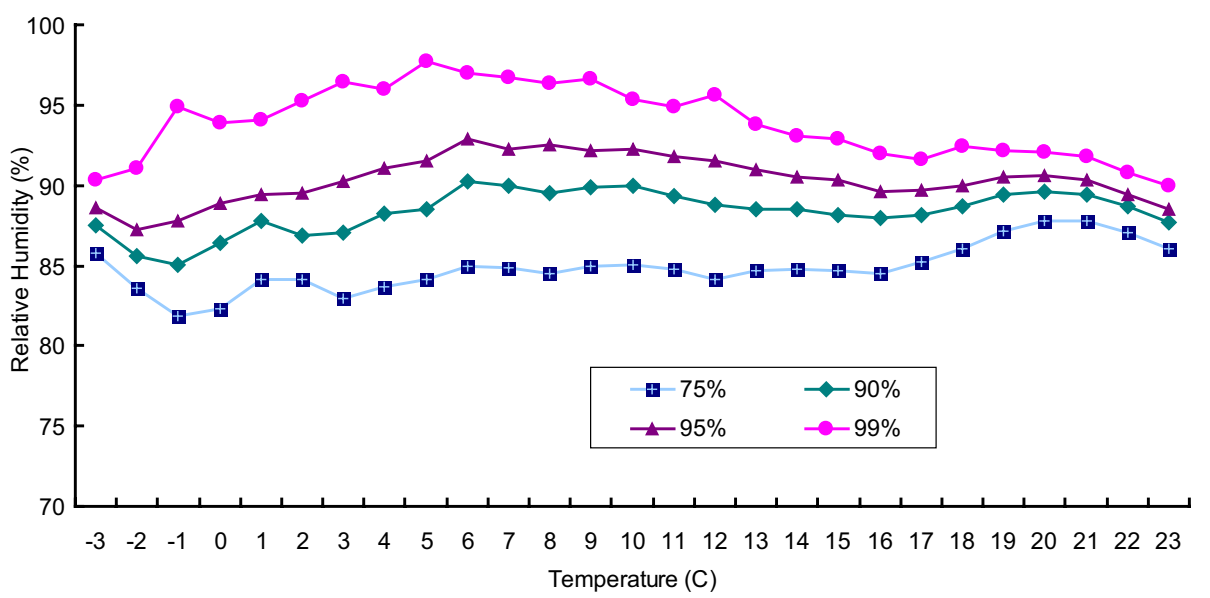


Fig. 11 Same as Fig. 8, but with latent heat flux

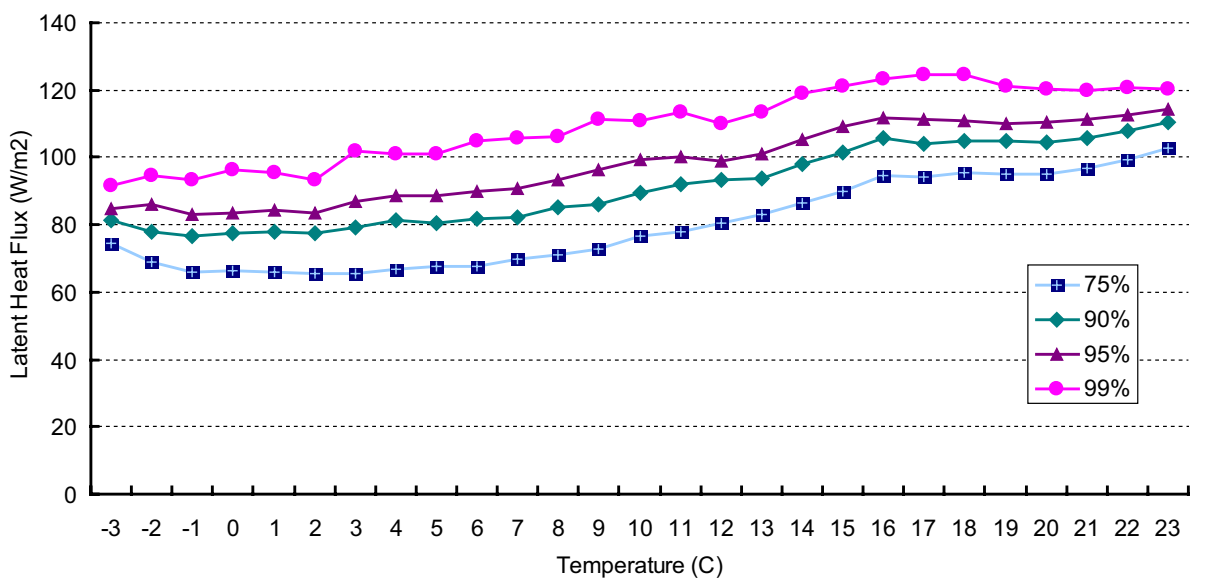

Fig. 12 Precipitation dependence on dew point temperature computed from ensemble experiments

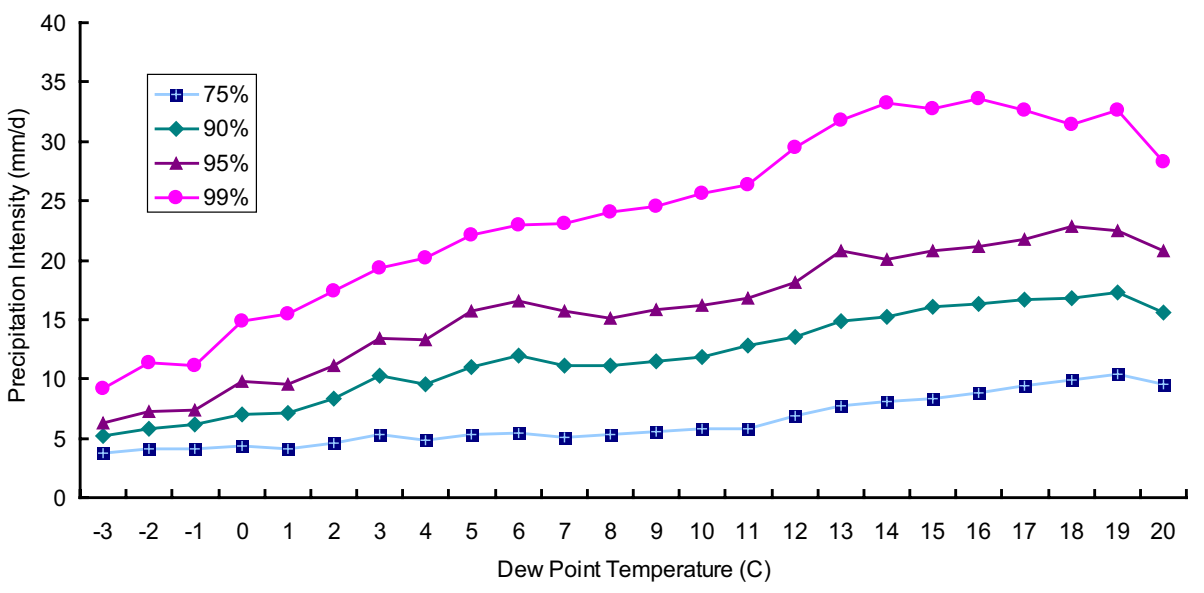

precipitation intensities are obtained for dew point temperature. Lenderink and van Meijgaard (2010) have also obtained similar patterns of extreme precipitation for temperature and dew point temperature over the Netherlands.

\subsection{Future increase of extreme precipitation intensities linked to temperature}

Our results also indicate that the rate of increase of extreme precipitation is higher in future climate scenarios compared to the current climate (see Sect. 4.4). This is projected in all of the ensemble members of the multi-model downscaling experiments. The projected future change in the increasing rate of precipitation intensities can be attributed to the increase of water vapor availability in the warmer atmosphere (Nayak and Dairaku 2016). The multi-model downscaling experiments show higher specific humidity (at $2 \mathrm{~m}$ ) in higher percentiles of extreme precipitation and the projected increase of specific humidity in future climate (Fig. 13). This should be seen as a major cause of the projected increased rate of extreme precipitation at higher percentiles.

Further we find that the gradual increase of the specific humidity with temperature (see Fig. 13) is not consistent with the decrease of precipitation intensity (Figs. 6, 9, 10, $11,12)$. This indicates that the projected increase of water vapor is not enough for saturation of air mass at higher temperatures to induce extreme precipitation; the rise in temperature does not increase the moisture availability endlessly in the atmosphere to trigger intense rainfall (Westra et al. 2014). It limits precipitation intensities after a specific temperature. This also can be due in part to the dynamic and thermodynamic influences on the atmospheric moisture content (Dairaku and Emori 2006; Pall et al. 2007).Thermodynamic changes due to an increase in the concentrations of greenhouse gases in the atmosphere modify the temperature and give rise to changes in water vapor availability. Similarly, dynamic changes due to the motion of atmospheric moisture content modify the nature of atmospheric circulation and alter the intensification of precipitation. Dynamics such as circulation patterns may suppress cloud formation and extreme precipitation. Another possible reason can be the evaporative cooling effect. When very heavy precipitation occurs, it increases the net water vapor storage for the first few hours (Zhao et al. 1997) and forces the air temperature to cool due to an evaporative cooling effect. A reason could also be associated with the soil moisture feedback to 
Fig. 13 Specific humidity (at $2 \mathrm{~m}$ ) as a function of $2 \mathrm{~m}$ air temperature in current and future climate scenarios

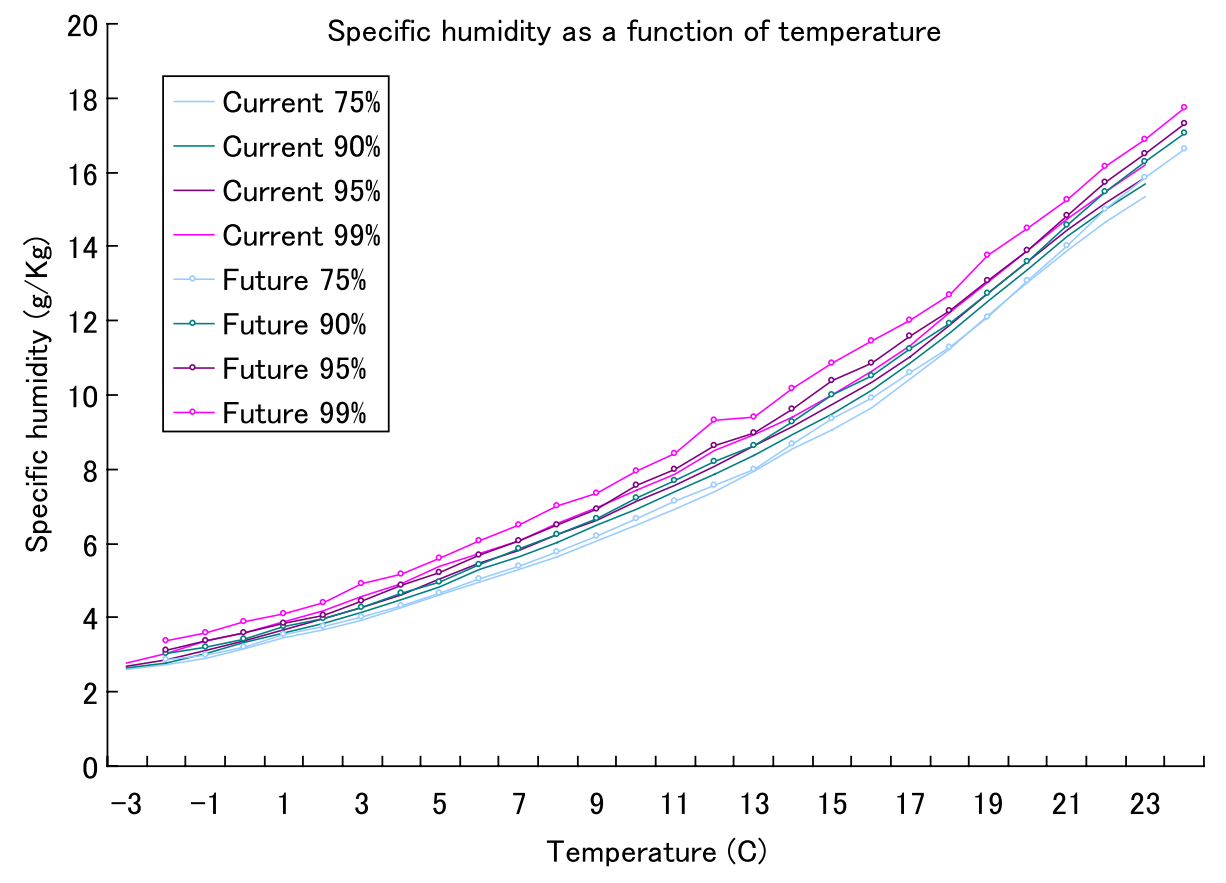

the atmosphere. Berg et al. (2015) highlighted that summertime-mean temperature and precipitation are negatively correlated due to the land-atmosphere interaction through soil moisture evapotranspiration. In general, evapotranspiration is controlled by the soil moisture availability or by atmospheric demand such as temperature, vapor pressure deficit and wind speed etc. Thus when soil moisture controls surface turbulent fluxes, the land-atmosphere feedback subsequently impacts on the low-level atmosphere (Seneviratne et al. 2006).

In our study, the CC scalings were investigated over Japan and we found that our results qualitatively agree with previous studies conducted over different Islands of Japan and other regions across the world. However, quantitatively, the relationship may be different at various regions because of the physical mechanisms of the precipitation and use of dataset at various time scales (sub-daily to daily). Daily precipitation dataset may not be sufficient to represent short duration rainfall events.

\section{Conclusions}

This study discussed regional climate responses over Japan by using multi-RCMs x multi-GCMs experiments to investigate extreme precipitation related to temperature in current and future climates.

We found the followings:

1. Simulated extreme precipitation linked to temperature from ensemble experiments agrees well with the obser- vation that a peak occurs around $19-22{ }^{\circ} \mathrm{C}$ for all percentiles of extreme precipitation.

2. $2 \mathrm{~m}$ air temperature is projected to increase by about $2{ }^{\circ} \mathrm{C}$ in climate scenarios in the late twenty-first century (RCP4.5).

3. A significant increase in precipitation under climate scenarios is projected for stronger precipitation intensities (above $15 \mathrm{~mm} /$ day), while a decrease in precipitation is projected for precipitation of $10-15 \mathrm{~mm} /$ day.

4. The projected change rate of the mean precipitation intensities with respect to mean temperature change over Japan is found to be $2.4 \% /{ }^{\circ} \mathrm{C}$.

5. An increase in stronger extreme precipitation is projected with the increase of temperature in climate scenarios. Extreme precipitation intensities (95th and 99th percentiles) are projected to increase by $5 \mathrm{~mm} / \mathrm{d}$ in the future climate for temperatures above $21^{\circ} \mathrm{C}$. The extreme precipitation intensities increase with temperatures up to $22{ }^{\circ} \mathrm{C}$ in the future climate, while the peak is $20^{\circ} \mathrm{C}$ for the current climate (about $2{ }^{\circ} \mathrm{C}$ warming shift).

6. Extreme precipitations of higher percentiles are projected to have larger increase rates in climate scenarios $\left(3-5 \% /{ }^{\circ} \mathrm{C}\right.$ in the current climate and $4-6 \% /{ }^{\circ} \mathrm{C}$ in the future climate).

7. A decrease in precipitation intensity at higher temperatures can be related to water vapor availability. Insufficient water vapor supply for saturation at higher temperatures can cause less formation of clouds and extreme precipitation. 
Responses such as a decrease in precipitation at higher temperatures can be dependent on the time-scale of precipitation (sub-daily or daily), seasons, and regions (Berg et al. 2009). We would like to further investigate sub-daily/ daily precipitations in different seasons and sub-regions over Japan, in particular to look at the relative importance of dynamic and thermodynamic (e.g., available water vapor) influences on extreme precipitation associated with an increase in temperature.

Acknowledgements This study was conducted as part of the research area "Vulnerability and Adaptation to Climate Change in Water Hazard Assessed Using Regional Climate Scenarios in the Tokyo Region" (National Research Institute for Earth Science and Disaster Prevention; PI: Koji Dairaku) of the Research Program on Climate Change Adaptation (RECCA), and was supported by the Program for Risk Information on Climate Change (SOUSEI) and Social Implementation Program on Climate Change Adaptation Technology (SI-CAT) Program, funded by the Ministry of Education, Culture, Sports, Science, and Technology, Government of Japan. We acknowledge the World Climate Research Programme's Working Group on Coupled Modelling, which is responsible for CMIP, and we thank the climate modeling groups (listed in Table 1) for producing and making available their model output.

Open Access This article is distributed under the terms of the Creative Commons Attribution 4.0 International License (http://creativecommons.org/licenses/by/4.0/), which permits unrestricted use, distribution, and reproduction in any medium, provided you give appropriate credit to the original author(s) and the source, provide a link to the Creative Commons license, and indicate if changes were made.

\section{References}

Alduchov OA, Eskridge RE (1996) Improved Magnus form approximation of saturation vapor pressure. J Appl Meteorol 35(4):601-609

Berg P, Haerter JO, Thejll P, Piani C, Hagemann S, Christensen JH (2009) Seasonal characteristics of the relationship between daily precipitation intensity and surface temperature. J Geophys Res 114:D18102

Berg A, Lintner BR, Findell K, Seneviratne SI, Hurk B, van den Ducharne A, Chéruy F, Hagemann S, Lawrence DM, Malyshev S, Meier A (2015) Interannual coupling between summertime surface temperature and precipitation over Land: processes and implications for climate change. J Clim 28(3):1308-1328

Boberg F, Christensen JH (2012) Overestimation of Mediterranean summer temperature projections due to model deficiencies. Nat Clim Chang 2(6):433-436

Dairaku K, Emori S (2006) Dynamic and thermodynamic influences on intensified daily rainfall during the Asian summer monsoon under doubled atmospheric $\mathrm{CO}_{2}$ conditions. Geophys Res Lett 33:L01704

Dairaku K, Emori S, Higashi H (2008a) Potential changes in extreme events under global climate change. J Disaster Res 3:39-50

Dairaku K, Emori S, Nozawa T (2008b) Impacts of global warming on hydrological cycles in the Asian monsoon region. Adv Atmos Sci 25:960-973

Gorman PA, Schneider T (2009) The physical basis for increases in precipitation extremes in simulations of 21 st-century climate change. Proc Natl Acad Sci 106(35):14773-14777
Hardwick JR, Westra S, Sharma A (2010) Observed relationships between extreme sub-daily precipitation, surface temperature, and relative humidity. Geophys Res Lett 37:L22805

Iizuka S, Dairaku K, Sasaki W, Ishizaki NN, Adachi SA, Kusaka H, Takayabu I (2012) Assessment of ocean surface winds and tropical cyclones around Japan by RCMs. J Meteorol Soc Jpn 90B:91-102

Iizumi T, Nishimori M, Dairaku K, Adachi SA, Yokozawa M (2011) Evaluation and intercomparison of downscaled daily precipitation indices over Japan in present-day climate: strengths and weaknesses of dynamical and bias-correction-type statistical downscaling methods. J Geophys Res 116:D01111

IPCC (2012) Managing the risks of extreme events and disasters to advance climate change adaptation. In: Field CB, Barros V, Stocker TF, Qin D, Dokken DJ, Ebi KL, Mastrandrea MD, Mach KJ, Plattner G-K, Allen SK, Tignor M, Midgley PM (eds) A special report of working groups I and II of the Intergovernmental Panel on Climate Change. Cambridge University Press, Cambridge, $\mathrm{p} 582$

IPCC (2007) Summary for policymakers, in Climate change 2007: the physical science basis. In: Solomon $\mathrm{S}$ et al. (eds) Contribution of working group I to the fourth assessment report of the Intergovernmental Panel on Climate Change. Cambridge University Press, Cambridge, pp 1-18

Ishizaki N, Takayabu I (2009) On the warming events over Toyama plain by using NHRCM. SOLA 5:129-132

Ishizaki NN, Takayabu I, Ooizumi M, Sasaki H, Dairaku K, Iizuka S, Kimura F, Kusaka H, Adachi SA, Kurihara K, Murazaki K, Tanaka K (2012) Improved performance of simulated Japanese climate with a multi-model ensemble. J Meteorol Soc Jpn 90:235-254

Kirtman BP, Min D, Infanti JM, Kinter JL III, Paolino DA, Zhang Q et al (2014) The North American multimodel ensemble: phase-1 seasonal-to-interannual prediction; phase-2 toward developing intraseasonal prediction. Bull Am Meteorol Soc 95(4):585-601

Kusaka H, Chen F, Tewari M, Dudhia J, Gill DO, Duda MG, Wang W, Miya Y (2012a) Numerical simulation of urban heat island effect by the WRF model with 4-km grid increment: an intercomparison study between the urban canopy model and slab model. J Meteorol Soc Jpn 90B:33-45

Kusaka H, Hara M, Takane Y (2012b) Urban climate projection by the WRFmodel at 3-kmhorizontal grid increment: dynamical downscaling and predicting heat stress in the 2070s August for Tokyo, Osaka, and Nagoya metropolies. J Meteorol Soc Jpn 90B:47-63

Lenderink G, Meijgaard E van (2008) Increase in hourly precipitation extremes beyond expectations from temperature changes. Nat Geosci 1(8):511-514

Lenderink G, Meijgaard E van (2010) Linking increases in hourly precipitation extremes to atmospheric temperature and moisture changes. Environ Res Lett 5(2):025208

Mishra V, Wallace JM, Lettenmaier DP (2012) Relationship between hourly extreme precipitation and local air temperature in the United States. Geophys Res Lett 39(16):L16403

Mizuta R, Arakawa O, Ose T, Kusunoki S, Endo H, Kitoh A (2014) Classification of CMIP5 future climate responses by the tropical sea surface temperature changes. SOLA 10(0):167-171

Nayak S, Dairaku K (2016) Future changes in extreme precipitation intensities associated with temperature under SRES A1B scenario. HRL 10(4):139-144

O'Groisman PY, Knight RW, Easterling DR, Karl TR, Hegerl GC, Razuvaev VN (2005) Trends in intense precipitation in the climate record. J Clim 18(9):1326-1350

Onogi K, Tsutsui J, Koide H, Sakamoto M, Kobayashi S, Hatsushika H, Matsumoto T, Yamazaki N, Kamahori H, Takahashi K, Kadokura S, Wada K, Kato K, Oyama R, Ose T, Mannoji N, Taira R (2007) The JRA-25 reanalysis. J Meteorol Soc Jpn 85:369-432 
Pall P, Allen MR, Stone DA (2007) Testing the Clausius-Clapeyron constraint on changes in extreme precipitation under $\mathrm{CO}_{2}$ warming. Clim Dyn 28(4):351-363

Pielke RA, Cotton WR, Walko RL, Tremback CJ, Lyons WA, Grasso LD, Nicholls ME, Moran MD, Wesley DA, Lee TJ, Copeland JH (1992) A comprehensive meteorological modeling system: RAMS. Meteorol Atmos Phys 49:69-91

Saito K, Fujita T, Yamada Y, Ishida J, Kumagai Y, Aranami K, Ohmori S, Nagasawa R, Kumagai S, Muroi C, Kato T, Eito H, Yamazaki Y (2006) The operational JMA nonhydrostatic mesoscale model. Mon Weather Rev 134:1266-1298

Seneviratne SI, Lüthi D, Litschi M, Schär C (2006) Land-atmosphere coupling and climate change in Europe. Nature 443:205-209

Shaw SB, Royem AA, Riha SJ (2011) The relationship between extreme hourly precipitation and surface temperature in different hydroclimatic regions of the United States. J Hydrol 12(2):319-325

Skamarock WC, Klemp JB, Dudhia J, Gill DO, Barker DM, Duda MG, Huang XY, Wang W, Powers JG (2008) A description of the advanced research WRF version 3. Tech Note TN-475 Natl Cent for Atmos Res, Boulder
Trenberth K, Dai A, Rasmussen R, Parsons D (2003) The changing character of precipitation. Bull Am Meteorol Soc 84(9):1205-1217

Tsunematsu U, Dairaku K, Hirano J (2013) Future changes in summertime precipitation amounts associated with topography in the Japanese islands. J Geophys Res Atmos 118(10):4142-4153

Utsumi N, Seto S, Kanae S, Maeda EE, Oki T (2011) Does higher surface temperature intensify extreme precipitation? Geophys Res Lett 38:L16708

Westra S, Fowler HJ, Evans JP, Alexander LV, Berg P, Johnson F, Kendon EJ, Lenderink G, Roberts NM (2014) Future changes to the intensity and frequency of short-duration extreme rainfall. Rev Geophys 52(3):522-555

Yasutomi N, Hamada A, Yatagai A (2011) Development of a longterm daily gridded temperature dataset and its application to rain/ snow discrimination of daily precipitation. Global Environ Res 15(2):165-172

Zhao W, Smith JA, Bradley AA (1997) Numerical simulation of a heavy rainfall event during the PRE-STORM Experiment. Water Resour Res 33(4):783-799 